\title{
Front Matter: Volume 7287
}

, "Front Matter: Volume 7287," Proc. SPIE 7287, Electroactive Polymer Actuators and Devices (EAPAD) 2009, 728701 (4 May 2009); doi: $10.1117 / 12.832664$

EDIE $\quad$ Event: SPIE Smart Structures and Materials + Nondestructive Evaluation and Health Monitoring, 2009, San Diego, California, United States 


\title{
PROCEEDINGS OF SPIE
}

\section{Electroactive Polymer Actuators and Devices (EAPAD) 2009}

\author{
Yoseph Bar-Cohen \\ Thomas Wallmersperger \\ Editors
}

\author{
9-12 March 2009 \\ San Diego, California, United States \\ Sponsored by \\ SPIE \\ Cosponsored by \\ American Society of Mechanical Engineers (United States) \\ Cooperating Organizations \\ Intelligent Materials Forum (Japan) \\ Jet Propulsion Laboratory (United States) \\ National Science Foundation (United States) \\ Published by \\ SPIE
}


The papers included in this volume were part of the technical conference cited on the cover and title page. Papers were selected and subject to review by the editors and conference program committee. Some conference presentations may not be available for publication. The papers published in these proceedings reflect the work and thoughts of the authors and are published herein as submitted. The publisher is not responsible for the validity of the information or for any outcomes resulting from reliance thereon.

Please use the following format to cite material from this book:

Author(s), "Title of Paper," in Electroactive Polymer Actuators and Devices (EAPAD) 2009, edited by Yoseph Bar-Cohen, Thomas Wallmersperger, Proceedings of SPIE Vol. 7287 (SPIE, Bellingham, WA, 2009) Article CID Number.

ISSN 0277-786X

ISBN 9780819475473

Published by

SPIE

P.O. Box 10, Bellingham, Washington 98227-0010 USA

Telephone +1 3606763290 (Pacific Time) · Fax +1 3606471445

SPIE.org

Copyright (@ 2009, Society of Photo-Optical Instrumentation Engineers

Copying of material in this book for internal or personal use, or for the internal or personal use of specific clients, beyond the fair use provisions granted by the U.S. Copyright Law is authorized by SPIE subject to payment of copying fees. The Transactional Reporting Service base fee for this volume is $\$ 18.00$ per article (or portion thereof), which should be paid directly to the Copyright Clearance Center (CCC), 222 Rosewood Drive, Danvers, MA 01923. Payment may also be made electronically through CCC Online at copyright.com. Other copying for republication, resale, advertising or promotion, or any form of systematic or multiple reproduction of any material in this book is prohibited except with permission in writing from the publisher. The CCC fee code is 0277-786X/09/\$18.00.

Printed in the United States of America.

Publication of record for individual papers is online in the SPIE Digital Library.

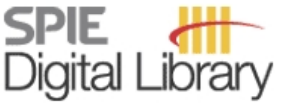

SPIEDigitalLibrary.org

Paper Numbering: Proceedings of SPIE follow an e-First publication model, with papers published first online and then in print and on CD-ROM. Papers are published as they are submitted and meet publication criteria. A unique, consistent, permanent citation identifier (CID) number is assigned to each article at the time of the first publication. Utilization of CIDs allows articles to be fully citable as soon they are published online, and connects the same identifier to all online, print, and electronic versions of the publication. SPIE uses a six-digit CID article numbering system in which:

- The first four digits correspond to the SPIE volume number.

- The last two digits indicate publication order within the volume using a Base 36 numbering system employing both numerals and letters. These two-number sets start with 00, 01, 02, 03, 04 , 05, 06, 07, 08, 09, OA, OB ... 0Z, followed by 10-1Z, 20-2Z, etc.

The CID number appears on each page of the manuscript. The complete citation is used on the first page, and an abbreviated version on subsequent pages. Numbers in the index correspond to the last two digits of the six-digit CID number. 


\title{
Contents
}

\author{
xi Symposium Committee \\ xiii Conference Committee \\ xvii Introduction \\ xix Paleoaerodynamic exploration of the evolution of nature's flyers and man's aircraft and \\ options for future technology innovations (Plenary Paper) [7288-104]* \\ B. M. Kulfan, The Boeing Co. (United States) \\ *This is an abridged version of Brenda Kulfan's plenary paper. A full-length version, including \\ figures, is published in volume 7288. The CID number is 728803.
}

\section{EAP AS EMERGING ACTUATORS AND BIOMIMETIC TECHNOLOGIES}

728702 The simulation of humans and lower animals (Keynote Paper) [7287-01]

D. Terzopoulos, Univ. of California, Los Angeles (United States)

$728703 \quad$ Electroactive polymer (EAP) actuators for future humanlike robots [7287-02]

Y. Bar-Cohen, Jet Propulsion Lab. (United States)

$728704 \quad H y d r o g e l$ research in Germany: the priority programme, Intelligent Hydrogels (Invited Paper) [7287-03]

T. Wallmersperger, Univ. Stuttgart (Germany); G. Sadowski, Technische Univ. Dortmund (Germany)

\section{BIOMIMETICS}

728706 FEA of dielectric elastomer minimum energy structures as a tool for biomimetic design [7287-04]

B. O'Brien, T. Gisby, Univ. of Auckland (New Zealand); E. Calius, Industrial Research Ltd. (New Zealand); S. Xie, I. Anderson, Univ. of Auckland (New Zealand)

728707 Integrated sensing and actuation of muscle-like actuators [7287-05]

T. A. Gisby, S. Xie, Univ. of Auckland (New Zealand); E. P. Calius, Industrial Research Ltd. (New Zealand); I. A. Anderson, Univ. of Auckland (New Zealand)

728708 Microbial-powered artificial muscles for autonomous robots [7287-06] I. Ieropoulos, Univ. of the West of England (United Kingdom) and Univ. of Bristol (United Kingdom); I. A. Anderson, T. Gisby, C. H. Wang, Univ. of Auckland (New Zealand); J. Rossiter, Univ. of the West of England (United Kingdom) and Univ. of Bristol (United Kingdom)

728709 Silicone based artificial skin for humanoid facial expressions [7287-07]

Y. Tadesse, D. Moore, N. Thayer, S. Priya, Virginia Polytechnic Institute and State Univ. (United States) 
7287 OA Contractive tension force stack actuator based on soft dielectric EAP (Invited Paper)

[7287-08]

G. Kovacs, L. Düring, Empa (Switzerland)

\section{ELECTRONIC EAP}

7287 OC Ion-implanted compliant electrodes for $\mathbf{m m}$-size dielectric elastomer actuators [7287-10] S. Rosset, M. Niklaus, P. Dubois, H. R. Shea, École Polytechnique Fédérale de Lausanne (Switzerland)

7287 OD Dielectric elastomer actuators with hydrostatic coupling [7287-11]

F. Carpi, G. Frediani, D. De Rossi, Univ. of Pisa (Italy)

7287 OG Closed-loop control of a core free rolled EAP actuator [7287-71]

R. Sarban, Danfoss PolyPower A/S (Denmark); J. Oubaek, R. W. Jones, Southern Denmark Univ. (Denmark)

$7287 \mathrm{OH} \quad$ Printing 3D dielectric elastomer actuators for soft robotics [7287-15]

J. Rossiter, Univ. of Bristol (United Kingdom); P. Walters, Univ. of the West of England, Bristol (United Kingdom); B. Stoimenov, RIKEN (Japan)

\section{DIELECTRIC EAP ACTUATORS}

$7287 \mathrm{Ol} \quad$ Experimental performance and feasibility of a miniature single-degree-of-freedom rotary joint with integrated IPMC actuator [7287-89]

S. Manley, A. McDaid, K. Aw, S. Xie, E. Haemmerle, Univ. of Auckland (New Zealand)

7287 OK Pulsatile dielectric elastomer membrane sensors [7287-19]

S. Son, N. C. Goulbourne, Virginia Polytechnic Institute and State Univ. (United States)

7287 OL Phthalocyanine and encapsulated polyaniline nanoparticles as fillers for dielectric elastomers [7287-20]

D. M. Opris, D. Crespy, C. Löwe, M. Molberg, F. Nüesch, Empa (Switzerland)

\section{FABRICATION AND CHARACTERIZATION OF EAP}

7287 ON Forced and free displacement characterization of ionic polymer transducers [7287-22] B. J. Akle, Lebanese American Univ. (Lebanon); A. Duncan, Virginia Polytechnic Institute and State Univ. (United States); E. Akle, Lebanese American Univ. (Lebanon);

T. Wallmersperger, Univ. Stuttgart (Germany); D. J. Leo, Virginia Polytechnic Institute and State Univ. (United States)

$728700 \quad$ Long lifetime dielectric elastomer actuators under continuous high strain actuation [7287-23] W. Yuan, P. Brochu, H. Zhang, A. Jan, Q. Pei, Univ. of California, Los Angeles (United States)

7287 OP The dielectric constant of 3M VHB: a parameter in dispute [7287-24]

T. G. McKay, Univ. of Auckland (New Zealand); E. Calius, Industrial Research Ltd.

(New Zealand); I. A. Anderson, Univ. of Auckland (New Zealand) 
$7287 \mathrm{OQ} \quad$ High $\mathrm{k}$ dielectric elastomeric materials for low voltage applications [7287-25]

C. Walder, Empa (Switzerland); M. Molberg, Empa (Switzerland) and École Polytechnique Fédérale de Lausanne (Switzerland); D. M. Opris, F. A. Nüesch, C. Löwe, Empa (Switzerland); C. J. G. Plummer, Y. Leterrier, J. E. Månson, École Polytechnique Fédérale de Lausanne (Switzerland)

7287 OR Scalable industrial manufacturing of DEAP [7287-26]

H.-E. Kiil, M. Benslimane, Danfoss PolyPower A/S (Denmark)

7287 OS Low voltage linear actuators based on carbide-derived carbon powder [7287-27]

J. Torop, Univ. of Tartu (Estonia); M. Arulepp, Univ. of Tartu (Estonia) and Carbon Nanotech, Ltd. (Estonia); J. Leis, Carbon Nanotech, Ltd. (Estonia) and Univ. of Tartu (Estonia);

A. Punning, U. Johanson, A. Aabloo, Univ. of Tartu (Estonia)

\section{IONIC EAP BASED ON IPMC}

7287 OT Investigating a few key issues of ionomeric polymer conductive network composite electromechanical transducers (Invited Paper) [7287-28]

S. Liu, M. Lin, Y. Liu, Q. Zhang, The Pennsylvania State Univ. (United States); R. Montazami, V. Jain, J. R. Heflin, Virginia Polytechnic Institute and State Univ. (United States)

7287 OU Modeling and experimental investigations of the sensitivity of piezoresistive chemical sensors based on polyelectrolytic hydrogels [7287-29]

M. Guenther, G. Gerlach, Technische Univ. Dresden (Germany); T. Wallmersperger, Univ. Stuttgart (Germany); V. Schulz, Technische Univ. Dresden (Germany)

7287 OV Dynamical variation of the impedances of IPMC [7287-30]

K. Kruusamäe, A. Punning, Tartu Univ. (Estonia); M. Kruusmaa, Tartu Univ. (Estonia) and Tallinn Univ. of Technology (Estonia); A. Aabloo, Tartu Univ. (Estonia)

7287 OW A novel ionic polymer-metal composites incorporating ZnO thin film [7287-31] S.-M. Kim, R. Tiwari, K. J. Kim, Univ. of Nevada, Reno (United States)

7287 OX Sulfonated polyamide based IPMCs [7287-32] I.-S. Park, Univ. of Nevada, Reno (United States); C. Bae, T. S. Jo, J. Truong, Univ. of Nevada, Las Vegas (United States); S.-M. Kim, K. J. Kim, Univ. of Nevada, Reno (United States); W. Yim, J.-S. Lee, Univ. of Nevada, Las Vegas (United States)

$7287 \mathrm{OY} \quad$ Focusing and negative refraction in anisotropic indefinite permittivity media [7287-92] S. Marshall, A. V. Amirkhizi, S. Nemat-Nasser, Univ. of California, San Diego (United States)

$7287 \mathrm{OZ} \quad$ Modeling and optimization of ionic polymer gel actuators [7287-34]

C. Jo, H. E. Naguib, R. H. Kwon, Univ. of Toronto (Canada)

IONIC EAP BASED ON IPMC, CNT, AND CP

728710 Cellulose electro-active paper: actuator, sensor, and beyond [7287-35]

J. Kim, S. Y. Yang, G.-Y. Yun, S. Jang, K. Yun, Inha Univ. (Korea, Republic of) 
728711 Electromechanical performance and membrane stability of novel ionic polymer transducers constructed in the presence of ionic liquids [7287-36]

A. J. Duncan, D. J. Leo, T. E. Long, Virginia Polytechnic Institute and State Univ. (United States); B. J. Akle, Lebanese American Univ. (Lebanon); J. K. Park, R. B. Moore, Virginia Polytechnic Institute and State Univ. (United States)

728712 In vitro investigations of a pH- and ionic-strength-responsive polyelectrolytic hydrogel using a piezoresistive microsensor [7287-37]

V. Schulz, M. Guenther, G. Gerlach, Technische Univ. Dresden (Germany); J. J. Magda,

P. Tathireddy, L. Rieth, F. Solzbacher, Univ. of Utah (United States)

728713 Solid electroytes for CNT-based actuators [7287-38]

J. Riemenschneider, S. Geier, T. Mahrholz, J. Mosch, H. P. Monner, M. Sinapius, Deutsches Zentrum für Luft- und Raumfahrt e.V. (Germany)

728714 Development and characterization of porous polypyrrole-polylactic acid electroactive polymer blends [7287-39]

C. Chan, E. Chan, H. E. Naguib, Univ. of Toronto (Canada)

MODELING AND ANALYSIS OF EAP

728715 Nonlinear capacitance of ionic polymer-metal composites [7287-40]

Z. Chen, D. R. Hedgepeth, X. Tan, Michigan State Univ. (United States)

728716 Modeling dynamics of underwater vehicles actuated by ionic polymer metal composite (IPMC) actuators [7287-41]

S. Gutta, W. Yim, M. B. Trabia, Univ. of Nevada, Las Vegas (United States)

728717 Hysteresis modelling of a core-free EAP tubular actuator [7287-42]

R. Sarban, J. Oubaek, Danfoss PolyPower A/S (Denmark); G. R. Kristjánsdóttir, R. W. Jones, Southern Denmark Univ. (Denmark)

728719 Stability analysis of dielectric elastomer using the elastic strain energy function with two material constants [7287-44]

L. Liu, Y. Liu, Z. Zhang, K. Yu, G. Deng, S. Sun, L. Shi, J. Leng, Harbin Institute of Technology (China)

7287 1A Capacitance boost in ionic polymer metal composites due to electrode surface roughness [7287-45]

M. Aureli, W. Lin, M. Porfiri, Polytechnic Institute of New York Univ. (United States)

7287 1B A comprehensive dynamic actuation model for ionic polymer-metal composites [7287-46] L. Zhang, Y. W. Yang, Nanyang Technological Univ. (Singapore)

\section{APPLICATION OF EAP TO ROBOTICS}

7287 1C Development of integrated tactile display devices (Invited Paper) [7287-47]

H. R. Choi, D. Kim, N. H. Chuc, N. H. L. Vuong, J. Koo, J. Nam, Y. Lee, Sungkyunkwan Univ. (Korea, Republic of) 
7287 1D Tactile display with dielectric multilayer elastomer actuators [7287-48]

M. Matysek, P. Lotz, H. F. Schlaak, Technische Univ. Darmstadt (Germany)

$72871 \mathrm{E} \quad$ The development of electrically driven mechanochemical actuators that act as artificial muscle (Invited Paper) [7287-49]

L. Rasmussen, C. J. Erickson, Ras Labs., LLC (United States); L. D. Meixler, Princeton Plasma Physics Lab. (United States)

7287 IF Powerful tubular core free dielectric electro activate polymer (DEAP) push actuator [7287-50]

M. Tryson, H.-E. Kiil, M. Benslimane, Danfoss PolyPower (Denmark)

7287 1G Jellyfish inspired unmanned underwater vehicle [7287-51]

A. Villanueva, S. Bresser, S. Chung, Y. Tadesse, S. Priya, Virginia Polytechnic Institute and State Univ. (United States)

$7287 \mathrm{1H} \quad$ A dielectric elastomer actuator thin membrane rotary motor [7287-52]

I. A. Anderson, Univ. of Auckland (New Zealand); E. P. Calius, Industrial Research Ltd. (New Zealand); T. Gisby, T. Hale, T. McKay, B. O'Brien, S. Walbran, Univ. of Auckland (New Zealand)

\section{APPLICATIONS OF EAP}

7287 11 Electrically-activated catheter using polypyrrole actuators: cycling effects [7287-60]

T. Mirfakhrai, T. Shoa, N. Fekri, J. D. Madden, Univ. of British Columbia (Canada)

7287 I J Conducting polymer actuator driven catheter: overview and applications [7287-61] T. Shoa, Univ. of British Columbia (Canada); N. R. Munce, V. Yang, Sunnybrook and Women's Health Sciences Ctr. (Canada); J. D. Madden, Univ. of British Columbia (Canada)

7287 1K Application of EAP materials toward a refreshable Braille display [7287-62] N. Di Spigna, P. Chakraborti, P. Yang, T. Ghosh, P. Franzon, North Carolina State Univ. (United States)

$72871 \mathrm{M} \quad$ Modeling of robotic fish propelled by an ionic polymer-metal composite caudal fin [7287-64]

Z. Chen, S. Shatara, X. Tan, Michigan State Univ. (United States)

7287 iN Positioning control of Nafion-Au ionic polymer metal composite: mechanism of IPMCs' residual deformation for positioning control) [7287-65]

A. Itoh, T. Tanaka, Y. Mori, Tokyo Denki Univ. (Japan)

\section{MODELING AND ANALYSIS OF EAP II}

728710 Large deformation modeling of swelling actuation in conjugated polymer systems [7287-53] Y. Fang, T. J. Pence, X. Tan, Michigan State Univ. (United States)

7287 IP Optimization of porous membrane core morphology for polypyrrole trilayer actuators [7287-54]

A. D. Price, H. E. Naguib, Univ. of Toronto (Canada) 
7287 IQ Distributed parameter system modeling of IPMC actuators with the electro-stress diffusion coupling theory [7287-55]

K. Takagi, Nagoya Univ. (Japan) and RIKEN (Japan); T. Osada, Nagoya Univ. (Japan);

K. Asaka, AIST (Japan) and RIKEN (Japan); Y. Hayakawa, Nagoya Univ. (Japan) and RIKEN (Japan); Z.-W. Luo, Kobe Univ. (Japan) and RIKEN (Japan)

\section{APPLICATIONS OF EAP TO OPTICAL DEVICES}

7287 IR Advances in shape-memory polymer actuation (Invited Paper) [7287-56]

J. Leng, Y. Liu, X. Lan, Harbin Institute of Technology (China)

7287 is Electrically conductive shape-memory polymer filled with Ni powder chains [7287-57]

X. Lan, Y. Liu, J. Leng, Harbin Institute of Technology (China)

7287 iT Novel thermoplastic elastomeric gels as high-performance actuators with no mechanical pre-strain [7287-58]

P. H. Vargantwar, T. K. Ghosh, R. J. Spontak, North Carolina State Univ. (United States)

7287 IU A new EAP based on electroosmotic flow: nastic actuators [7287-59]

M. E. Piyasena, B. Shapiro, E. Smela, Univ. of Maryland, College Park (United States)

POSTER SESSION

7287 IV Silicone dielectric elastomers filled with carbon nanotubes and actuator [7287-13]

Z. Zhang, L. Liu, G. Deng, S. Sun, Y. Liu, J. Leng, Harbin Institute of Technology (China)

7287 IW Effect of organo-clay on actuation response of silicone rubber actuators [7287-66]

N. Gharavi, M. Razzaghi Kashani, A. Moradi, Tarbiat Modares Univ. (Iran, Islamic Republic of)

7287 1X A study of the dielectrophoresis force of elastomeric materials for artificial muscle applications [7287-67]

R. Kunanuruksapong, A. Sirivat, Chulalongkorn Univ. (Thailand)

7287 IY Modeling and experimental verification of a dielectric polymer energy scavenging cycle [7287-68]

Y. H. Iskandarani, R. W. Jones, E. Villumsen, Southern Denmark Univ. (Denmark)

728712 Creep effect modeling for a core free tubular actuator [7287-69]

R. Sarban, J. Oubaek, Danfoss PolyPower A/S (Denmark), R. W. Jones, Southern Denmark Univ. (Denmark)

728720 Development of multilayer conducting polymer actuator for power application [7287-70] K. Ikushima, Y. Kudoh, M. Hiraoka, K. Yokoyama, S. Nagamitsu, Panasonic Corp. (Japan)

728721 Postgraduate education on electro-active polymers at Southern Denmark University [7287-73]

R. W. Jones, Southern Denmark Univ. (Denmark) 
728722 Performance enhancement of IPMC by anisotropic plasma etching process [7287-74] S.-H. Lee, C.-J. Kim, H.-W. Hwang, S.-J. Kim, H.-S. Yang, N.-C. Park, Y.-P. Park, Yonsei Univ. (Korea, Republic of); K.-H. Park, H.-K. Lee, N.-J. Choi, Electronics and Telecommunications Research Institute (Korea, Republic of)

728723 Linear modeling of elongated bending EAP actuator at large deformations [7287-75] I. Must, Tartu Univ. (Estonia); M. Anton, Tartu Univ. (Estonia) and Michigan State Univ. (United States); M. Kruusmaa, Tartu Univ. (Estonia) and Tallinn Univ. of Technology (Estonia); A. Aabloo, Tartu Univ. (Estonia)

728724 Optimization of electrode placement in electromyographic control of dielectric elastomers [7287-76]

S. H. Walbran, Univ. of Auckland (New Zealand); E. P. Calius, Industrial Research Ltd. (New Zealand); G. R. Dunlop, Univ. of Auckland (New Zealand) I. A. Anderson, Univ. of Auckland (New Zealand)

728725 A model of the IPMC actuator using finite element method [7287-78] C.-J. Kim, N.-C. Park, H.-S. Yang, Y.-P. Park, Yonsei Univ. (Korea, Republic of); K.-H. Park, H.-K. Lee, N.-J. Choi, Electronics and Telecommunications Research Institute (Korea, Republic of)

728726 Performance improvement of IPMC using resonance frequency [7287-79] H. Hwang, S. Kim, C.-J. Kim, H. Yang, N. C. Park, Y.-P. Park, Yonsei Univ. (Korea, Republic of)

728727 Ionic liquids adsorbed cellulose electro active paper actuator [7287-80] S. K. Mahadeva, J. Nayak, J. Kim, Inha Univ. (Korea, Republic of)

728728 Coupled electro-mechanical response of an electroactive polymer cantilever structure and its application in energy harvesting [7287-81]

B. Ahish, S. V. Anand, Indian Institute of Science (India); P. Bharath, K. Arvind, BMS College of Engineering (India); N. Chakraborty, D. Roy Mahapatra, Indian Institute of Science (India)

728729 The influence of mechanical properties in the electrical breakdown in poly-styreneethylene-butadiene-styrene thermoplastic elastomer [7287-82] M. Kollosche, M. Melzer, A. Becker, H. Stoyanov, D. N. McCarthy, H. Ragusch, G. Kofod, Univ. Potsdam (Germany)

7287 2A Bio-inspired tactile sensor with arrayed structures based on electroactive polymers [7287-84]

J. Wang, Univ. of Washington (United States); H. Sato, Univ. of Washington (United States) and AIST (Japan); M. Taya, Univ. of Washington (United States)

$72872 \mathrm{~B}$ Soft ionic polymer metal composite (IPMC) robot swimming in viscous fluid [7287-85] B. L. Stoimenov, RIKEN (Japan); J. Rossiter, Univ. of Bristol (United Kingdom); T. Mukai, RIKEN (Japan)

7287 2C Integrated gas valve array using dielectric elastomer actuators [7287-87] K. Flittner, P. Lotz, M. Matysek, M. Schlosser, H. F. Schlaak, Technische Univ. Darmstadt (Germany) 
7287 2D Peristaltic pump made of dielectric elastomer actuators [7287-88]

P. Lotz, M. Matysek, H. F. Schlaak, Technische Univ. Darmstadt (Germany)

7287 2E Performance of polymer-steel sandwich structures under blast loads [7287-91]

A. Samiee, J. Isaacs, S. Nemat-Nasser, Univ. of California, San Diego (United States)

Author Index 


\title{
Symposium Committee
}

\author{
Symposium Chairs
}

Alison B. Flatau, University of Maryland, College Park (United States)

George Y. Baaklini, NASA Glenn Research Center (United States)

Donald J. Leo, Virginia Polytechnic Institute and State University

(United States)

Kara J. Peters, North Carolina State University (United States)

Executive Committee

Mehdi Ahmadian, Virginia Polytechnic Institute and State University (United States)

Yoseph Bar-Cohen, Jet Propulsion Laboratory (United States)

Jung-Chih Chiao, The University of Texas at Arlington (United States)

Aaron A. Diaz, Pacific Northwest National Laboratory (United States)

Wolfgang Ecke, Institut für Physikalische Hochtechnologie e.V. (Germany)

Mehrdad N. Ghasemi-Nejhad, University of Hawaili at Manoa (United States)

Victor Giurgiutiu, University of South Carolina (United States)

Benjamin K. Henderson, Air Force Research Laboratory (United States)

Kumar V. Jata, Air Force Research Laboratory (United States)

Tribikram Kundu, The University of Arizona (United States)

Jiangyu Li, University of Washington (United States)

Douglas K. Lindner, Virginia Polytechnic Institute and State University (United States)

M. Brett McMickell, Honeywell, Inc. (United States)

Norbert Meyendorf, University of Dayton (United States)

Zoubeida Ounaies, Texas A\&M University (United States)

Peter J. Shull, The Pennsylvania State University (United States)

Kyo D. Song, Norfolk State University (United States)

Masayoshi Tomizuka, University of California, Berkeley (United States)

Vijay K. Varadan, University of Arkansas (United States)

Dietmar W. Vogel, Fraunhofer-Institut für Zuverlässigkeit und Mikrointegration (Germany)

Thomas Wallmersperger, Universität Stuttgart (Germany)

H. Felix Wu, National Institute of Standards and Technology (United States)

Chung-Bang Yun, Korea Advanced Institute of Science and Technology (Korea, Republic of) 
Proc. of SPIE Vol. 7287 728701-12

Downloaded From: https://www.spiedigitallibrary.org/conference-proceedings-of-spie on 26 Apr 2023 Terms of Use: https://www.spiedigitallibrary.org/terms-of-use 


\title{
Conference Committee
}

\author{
Conference Chair \\ Yoseph Bar-Cohen, Jet Propulsion Laboratory (United States) \\ Conference CoChair \\ Thomas Wallmersperger, Universität Stuttgart (Germany)
}

\section{Program Committee}

Barbar J. Akle, Lebanese American University (Lebanon)

Ray H. Baughman, The University of Texas at Dallas (United States)

Václav Bouda, Czech Technical University in Prague (Czech Republic)

Emilio P. Calius, Industrial Research Limited (New Zealand)

Federico Carpi, Università di Pisa (Italy)

Toribio Fernandez-Otero, Universidad Politécnica de Cartagena (Spain)

Edwin W. H. Jager, Linköpings Universitet (Sweden)

Keiichi Kaneto, Kyushu Institute of Technology (Japan)

Jaehwan Kim, Inha University (Korea, Republic of)

Kwang J. Kim, University of Nevada, Reno (United States)

Gabor M. Kovacs, EMPA Dübendorf (Switzerland)

Roy D. Kornbluh, SRI International (United States)

Maarja Kruusmaa, University of Tartu (Estonia)

Jinsong Leng, Harbin Institute of Technology (China)

Wen-Liang Liu, Industrial Technology Research Institute (Taiwan)

John D. W. Madden, The University of British Columbia (Canada)

Jaedo Nam, Sungkyunkwan University (Korea, Republic of)

Siavouche Nemat-Nasser, University of California, San Diego

(United States)

Qibing Pei, University of California, Los Angeles (United States)

Subramaniam Radhakrishnan, National Chemical Laboratory (India)

Jonathan M. Rossiter, University of Bristol (United Kingdom)

Peter Sommer-Larsen, Danmarks Tekniske Universitet (Denmark)

Ji Su, NASA Langley Research Center (United States)

Minoru Taya, University of Washington (United States)

Gordon G. Wallace, University of Wollongong (Australia)

Gary Zaiats, Rafael Armament Development Authority, Ltd. (Israel)

Qiming Zhang, The Pennsylvania State University (United States) 


\section{Session Chairs}

1 EAP as Emerging Actuators and Biomimetic Technologies Yoseph Bar-Cohen, Jet Propulsion Laboratory (United States) Thomas Wallmersperger, Universität Stuttgart (Germany)

2 Biomimetics Iain A. Anderson, The University of Auckland (New Zealand) Gabor M. Kovacs, EMPA (Switzerland)

3 EAP-in-Action Demonstration

Yoseph Bar-Cohen, Jet Propulsion Laboratory (United States)

4 Electronic EAP

Barbar J. Akle, Lebanese American University (Lebanon) Thomas Wallmersperger, Universität Stuttgart (Germany)

5 Dielectric EAP Actuators

Federico Carpi, Università di Pisa (Italy)

Tissaphern Mirfakhrai, The University of British Columbia (Canada)

6 Fabrication and Characterization of EAP

Minoru Taya, University of Washington (United States)

Stewart Sherrit, Jet Propulsion Laboratory (United States)

7 Ionic EAP Based on IPMC

Gerald U. Gerlach, Technische Universität Dresden (Germany)

Alireza Vakil Amirkhizi, University of California, San Diego (United States)

8 Ionic EAP Based on IPMC, CNT, and CP

Xiaobo Tan, Michigan State University (United States)

Kwang J. Kim, University of Nevada, Reno (United States)

9 Modeling and Analysis of EAP

Xuanhe Zhao, Harvard University (United States)

Elisabeth Smela, University of Maryland, College Park (United States)

10 Application of EAP to Robotics

Lenore Rasmussen, Ras Laboratory, LLC (United States)

Emilio P. Calius, Industrial Research, Ltd. (New Zealand)

11 Applications of EAP

Jaehwan Kim, Inha University (Korea, Republic of)

Jonathan M. Rossiter, University of Bristol (United Kingdom) 
12 Modeling and Analysis of EAP II

Zheng Chen, Michigan State University (United States)

Alireza Vakil Amirkhizi, University of California, San Diego

(United States)

13 Applications of EAP to Optical Devices

Hyouk Ryeol Choi, Sungkyunkwan University (Korea, Republic of)

Hani E. Naguib, University of Toronto (Canada) 
Proc. of SPIE Vol. 7287 728701-16

Downloaded From: https://www.spiedigitallibrary.org/conference-proceedings-of-spie on 26 Apr 2023 Terms of Use: https://www.spiedigitallibrary.org/terms-of-use 


\section{Introduction}

The large displacement that can be produced by EAP materials and their functional similarity to biological muscles are increasingly attracting the interest of researchers from many fields. Turning these materials into actuators-of-choice continues to require solidifying the technical foundations. Also, it is essential to identify niche applications for EAP materials where their unique capabilities would provide an edge for critical needs. This SPIE Electroactive Polymers Actuators and Devices (EAPAD) Conference serves as the leading international forum for presenting the latest in progress and discussions among the attendees regarding capabilities, challenges, and potential future directions.

The Keynote speaker was Demetri Terzopoulos, (Univ. of California, Los Angeles), and the title of his presentation was "The simulation of humans and lower animals". In his presentation he described a neuromuscular control model that emulates relevant biological motor control mechanisms. Employing machine learning techniques, the neural networks within his neuromuscular controllers are trained offline to efficiently generate the pose and stiffness control signals necessary to synthesize a variety of autonomous human movements. Examples of simulation videos where shown in Terzopoulos's presentation and illustrated the level of life-like performance that was achieved.

The conference this year included 66 presentations and was well attended by leading world experts in the field including members of academia, industry, and government agencies from the USA and overseas. Significant progress was reported in each of the topics of the EAP infrastructure. The papers focused on issues that can forge the transition to practical use, including improved materials, better understanding of the principles responsible for the electromechanical behavior, analytical modeling, processing and characterization methods as well as considerations and demonstrations of various applications. A special session was dedicated this year to the topic of Biomimetics and was chaired by lain A. Anderson, (The Univ. of Auckland, New Zealand), and Gabor M. Kovacs, (EMPA, Switzerland). Other topics that were covered in this conference included:

- Electroactive polymers (EAP) and non-electro active-polymer (NEAP) materials

- Theoretical models, analysis and simulation of EAP

- Methods of testing and characterization of EAP

- EAP as artificial muscles, actuators and sensors

- Design, control, intelligence, and kinematic issues related to robotic and biomimetic operation of EAP

- Under consideration and in progress applications of EAP

The efforts described in the presented papers show significant improvements in the understanding of electromechanical principles and better methods of dealing with challenges to materials applications. Researchers are continuing to develop 
analytical tools and theoretical models to describe electro-chemical and mechanical processes, non-linear behavior as well as methodologies of design and control of activated materials. EAP, with improved response, was described including dielectric elastomer, electrostrictive, IPMC, carbon nanotubes, conductive polymers, and other types. There has been a great improvement in the automation of the manufacturing of EAP (including Danfoss and EMPA) reducing the reliance on hand made fabrications. Further, there is a significant trend towards the use of dielectric elastomers as practical EAP actuators.

This year, the EAP-in-Action Session was held on Monday, March 9, 2009 and it included five demonstrations by organizations from Denmark, Italy, New Zealand, Switzerland, and USA. The presenters included the Auckland Bioengineering Institute's Biomimetics Lab, New Zealand; Danfoss PolyPower A/S, Nordborg, Denmark; Materials Science \& Technology, EMPA, Switzerland; Ras Labs, LLC, Intelligent Materials for Prosthetics \& Robotics, Hillsborough, NJ, USA; and Research Centre "E. Piaggio", University of Pisa, Italy.

To provide the attendees with the opportunity to learn about EAP, an introductory course was given on Sunday, March 8, 2009 as part of the EAPAD Conference. The course was entitled "Electroactive Polymer Actuators and Devices," and the lead instructor was the Conf. Chair, Yoseph Bar-Cohen, who presented an overview, and covered applications that are currently developed and ones that are being considered. The subject of Ionic EAP was covered by John D. W. Madden, (The Univ. of British Columbia, Canada), while the topic of Electronic EAP was covered by Qibing Pei, (University of California, Los Angeles). This course was intended for engineers, scientists and managers who need to understand the basic concepts of EAP, or are interested in learning, applying or engineering mechanisms or devices using EAP materials. It was also intended for those who are considering research and development in EAP materials and their present and/or future applications. For those who are seeking to self-learn about EAP, a comprehensive coverage of the topic is given in the $2^{\text {nd }}$ Edition of the book that was published by SPIE Press entitled "Electroactive Polymers (EAP) actuators as artificial muscles" [http://ndeaa.jpl.nasa.gov/nasa-nde/yosi/yosi-books.htm], as well as the WW-EAP webhub: [http://eap.jpl.nasa.gov] with links to the leading research and development labs worldwide, and the WW-EAP Newsletter.

In closing, we would like to extend a special thanks to all the conference attendees, session chairs, the EAP-in-Action demo presenters, and the members of the EAPAD program organization committee. In addition, special thanks are extended to the SPIE staff that helped make this conference a great success. 


\title{
Paleoaerodynamic Exploration of the Evolution of Nature's Flyers and Man's Aircraft and Options for Future Technology Innovations ${ }^{+}$
}

\author{
Brenda M. Kulfan* \\ Boeing Commercial Airplanes, P.O. Box 3707 MC 67-LF, Seattle, WA, USA 98124-2207
}

\begin{abstract}
Insights and observations of fascinating aspects of birds, bugs and flying seeds, of inspired aerodynamic concepts, and visions of past, present and future aircraft developments are presented. The evolution of nature's flyers, will be compared with the corresponding evolution of commercial aircraft. We will explore similarities between nature's creations and man's inventions. Many critical areas requiring future significant technology based solutions remain. With the advent of UAVs and MAVs, the gap between "possible" and "actual" is again very large. Allometric scaling procedures will be used to explore size implications on limitations and performance capabilities of nature's creations. Biologically related technology development concepts including: bionics, biomimicry, neo-bionic, pseudo-mimicry, cybernetic and non-bionic approaches will be discussed and illustrated with numerous examples. Technology development strategies will be discussed along with the pros and cons for each. Future technology developments should include a synergistic coupling of "discovery driven", "product led" and "technology acceleration" strategies. The objective of this presentation is to inspire the creative nature existing within all of us. This is a summary all text version of the complete report with the same title that report includes approximately 80 figures, photos and charts and much more information.
\end{abstract}

Keywords: Nature's flyers, evolution, aircraft technology, bionic, biomimicry, neo-bionic, pseudo-mimicry, cybernetics, allometric scaling, innovation strategies

\section{INTRODUCTION}

In this presentation we will attempt to get a glimpse of insights and observations of some fascinating aspects of birds, insects and flying seeds, of inspired aerodynamic concepts, as well as visions of past, present and future aircraft developments and further opportunities for aircraft innovations. Through this brief journey for understanding, we will explore the fascinations of nature, the struggle to fly and the ultimate successes of our flying machines. At times our path may seem to wander from seeming unrelated thought to unrelated thought. However in each bend in the road it is hoped we will gain a greater insight and greater appreciations of nature, and of our industry.

Man most certainly has always been fascinated, and inspired by the dream of flying by observing birds soaring in the sky and flittering from tree to tree. The British aviation pioneer Sir Hiram Maxim once wrote: "Man is essentially a land animal and it is quite possible if Nature had not placed before him numerous examples of birds and insects that are able to fly, he would never have thought of attempting it himself". Many of mans flying or gliding inventions have indeed been inspired by natures creations.

We will briefly look and discuss various perspectives of the evolution Nature's flyers and the evolution of man's aircraft. An interesting view of the contrasting evolution-of-flight driving forces between nature and commercial aircraft will be introduced. We will explore many of nature's fascinating flying things including birds, insects and seeds and will also shows similarities between Nature's creations and Man's inventions. In spite of the tremendous technological growth leading to today's' aircraft, there remains many critical areas requiring future significant technology based solutions. With the advent of UAVs and MAVs, the gap between "possible" and "actual" is once again very large. Various technology development strategies will be discussed along with the pros and cons for each. It will be shown that future technology developments should include a synergistic coupling of "discovery driven", "product led" and "technology acceleration" strategies.

*brenda,m,kulfan@boeing.com; phone 1425 237-2650; fax 1425 237-2666

+ This is an abridged version of Brenda Kulfan's plenary paper. A full-length version, including figures, is published in volume 7288. The CID number is 728803. 
Biologically based technology development options will be discussed. Allometric scaling procedures will be used to explore size implications on limitations and performance capabilities of nature's flyers and nature in general. We will look at nature related sources and opportunities for future innovative developments where biomics, bio-mimicry, neobionic, non-bionic, Pseudo-Mimicry and cybernetics concepts of innovation are introduced and discussed. The importance of learning to see and not just look, and learning to hear and not just hear, and learning to wonder why and then conceive how it might apply, will be offered as key success elements for advancing our state of the art and science.

\section{EVOLUTION}

The evolution of flight in animals and in man's flying vehicles has steadily progressed over a period of time of approximately 330 millions of years starting with the first winged insects. Pterosaurs followed nearly 140 millions of years later. The earliest bird like animals first appeared 150 millions ago followed by early flowering plants many of which have exploited flight like mechanisms to disperse their seeds. Modern insect orders, modern bird orders and bats made their appearance about 55 to 75 millions of years ago. This corresponds to the Cretaceous /Tertiary Mass Extinction Event which occurred approximately 65 millions of years ago. Successful powered flight by man has existed over a minuscule period of slightly more than 100 years.

The process of evolution can be described as a gradual unrelenting improvement of living systems in response to local environmental conditions. The process of evolution in contrast to man's technology developments, does not "design" by working to specific goals or objectives, instead, evolution blindly cobbles together myriad random experiments over thousand of generations resulting in wonderfully elegant organisms whose goal is to stay alive long enough to produce the next generation which then launch the next round of random experiments.

The nature of the evolutionary processes of biological systems is fundamentally limiting since every new feature must develop from an existing feature. Consequently, there is no chance of making the sudden great revolutionary technology developments that are so common in the history of technology.

The grandfather of Charles Darwin, Erasmus Darwin published in his book "Zoonomia" in 1795 early thoughts on the origin of life. Erasmus Darwin wrote that warm-blooded creatures developed from "one living filament" and acquired new parts "in response to stimuli" and that all improvements were inherited by successive generations.

Jean-Baptiste Lamark in 1809, published his beliefs on the origin of life in "Philosophie Zoologique". Lamarck incorporated two ideas into his theory of evolution that in his day were generally considered true. Lamark believed that individuals develop characteristics that are useful in response to specific needs and these characteristics were retained by usage. He also believed that individuals lose characteristics they do not require (or use). Subsequent generations were thought to inherit all acquired traits. These unique beliefs of Lamark were ultimately disproved.

Charles Darwin published the "Origin of Species" in 1859 in which he defined that the process of "natural selection", (which is commonly called the survival of the fittest), occurring over millions of years has resulted in all the species of life. This is generally considered to be one of the greatest scientific discoveries of all time 5 . It was once stated "that never has so much knowledge been based on so little facts".

Gregor Mendel defined the statistical laws of inheritance. The notion of a gene has evolved with the science of genetics, which began when Gregor Mendel noticed that biological variations are inherited from parent organisms as specific, discrete traits. The biological entity responsible for defining traits was termed a gene. Prior to Mendel's work, the dominant theory of heredity was one of blending inheritance, which proposes that the traits of the parents blend or mix in a smooth, continuous gradient in the offspring.

Thomas Morgan (1912c) identified that genes carried on chromosomes defined the mechanical basis of heredity. He is generally considered to be the father of the modern science of genetics. The biological basis for inheritance remained unknown until DNA was identified as the genetic material in the 1940s. DNA not only confirmed the reality of evolution, it also showed at the most basic level how it reshapes living things. All organisms have many genes corresponding to many different biological traits. In cells, a gene is a portion of DNA that contains both "coding" sequences that determine what the gene does, and "non-coding" sequences that determine when the gene is active (expressed). James Watson and Francis Crick in 1953, defined the double helix structure of DNA. This discovery unlocked the mystery of how genetic information is passed from one generation to the next. 
Research studies by Peter and Rosemary Grant, (1970c) demonstrated that natural selection can cause evolutionary change in real time rather than only over thousands of years as Darwin had believed. More recent studies have shown evolution works not just by changing genes, but by modifying the way those genes are turned on and off by a "genetic switch". It therefore appears that the primary source for evolution turns out not to be gene changes but changes in the regulation of genes that control development. For example, a giraffe does not have special genes to make a long neck. Its neck growing genes are the same as those for a mouse; they are just switched on for a longer time.

Mice and humans (indeed, most or all mammals including dogs, cats, rabbits, monkeys, and apes) have approximately 29000 genes. In addition many of the same genes control similar functions on the different species.

The current understanding of the evolution life indicates that four conditions must be met in order for a species to exist:

- It must work mechanically and chemically

- It must be capable of being coded

- It must be able to survive at all stages of growth

- Its design must be able to be evolved through a series of forms from some other existing form, each form being viable in its own niche of the nichewise progression

\section{COEVOLUTION}

Coevolution is one of the most powerful driving forces in evolution. Coevolution involves the joint evolution of two or more species as a consequence of their ecological interaction. Each species in a coevolutionary relationship exerts strong selective pressures on the other, thereby affecting each others evolution. The close, prolonged association between two or more different organisms of different species that may, but does not necessarily, benefit each member is called symbiosis. The major types of co-evolutionary relationships include:

1. Mutualism which is a cooperative coevolutionary symboitic relationship in which both species benefit.

2. Predation which is a competitive coevolutionary relationship between a predator and its prey.

3. Amensalism which is a symbiotic coevolutionary relationship between organisms in which one species is harmed or inhibited and the other species is unaffected.

4. Commensalism which is a symbiotic coevolutionary relationship between two species in which one derives some benefit while the other is unaffected.

Examples of two types of mutualism relationships include bumble bees or hummingbirds and flowers. Bumblebees as well as hummingbirds both obtain nourishment from flowers and various trees and in the process they spread pollen to other trees and pollen. This is an example of a service-resource relationship. An example of service - service symbiosis is the relationship between clownfish that dwell among the stinging tentacles of sea anemones without being harmed. This protects the clownfish from larger predators and at the same time the clownfish protect the anemones from the butterfly fish which other wise would destroy them.

Aposematism which is most commonly known in the context of warning coloration describes anti-predator adaptations where a warning signal of potential danger or discomfort associated with a potential prey item to potential predators. It is one form of natures "advertising" signals, with many others such as the bright colors of flowers which lure pollinators. The warning signal may take the form of conspicuous colors, sounds, odors or other perceivable characteristics. Aposmatic signals are beneficial for both the predator and prey, who both avoid potential harm. Aposematic evolutionary developments can occur in many species of mammals, insects, reptiles and fish. The bright colors of the yellow-winged darter dragonfly, warns of its noxious taste. The pronounced black and white colors of the skunk warn of its noxious smell. The bright colors of the cuttlefish and the coral snake are warnings of toxicity.

Mimicry in nature is generally another form of mutualism. The yellow jacket and the bumblebee both share the same aposematic contrasting black and yellow coloring that warn of their painful stings. because of the similar colorings they share in the "education" of their potential predators. This is called Mullerian mimicry. The hoverfly which is harmless, has the same color pattern as the yellow jacket and the bumblebee and therefore exploits the safety provided by resembling them. This is called Batesian mimicry. 
An example of predator - prey coevolutionary development is that of the bat and the moth. Bats developed their sense of echolocation in part, to locate moths. Moths subsequently developed a soft surface coating to absorb the bat chirps. The bats in turn, developed new chirp frequencies to detect soft covering. Moths then responded by developing enhanced stealth characteristics and jamming technique (bug chirps). They also developed new evasive maneuvers. The bats then responded by developing new elaborate flight paths and the ability to turn echolocation off / on in order to confuse the moths. The arms race continues.

\section{EVOLUTION OF NATURES FLYERS}

Flight is one of the most demanding adaptations found in nature because of the physical challenges of moving in air under the persistent influence of gravity. Therefore flyers in nature have been subjected to strong selection for optimum morphology. Nature has, however, evolved four convergent solutions for the challenge of flight. These include birds, bats, pterosaurs and insects. Bats, birds, and pterodactyl wings not only perform the same function of providing the means of flight, but they are also examples of homologous structures since the limbs of all these organisms contain many of the same sets of bones. These have been passed downed to all these different animals from a common ancestor. These wings are also homologous to the human arm and hand. The wings of insects are analogous structures relative to the other previously discussed wings because of the fundamental differences in their internal anatomy even though they perform the similar function of flight.

Other nature fliers include the seeds of wind pollinating plants that evolved to provide their parent species one of the most remarkable and effective of all seed dispersal methods, riding the wind and air currents of the world. Some common examples are the milkweed seed, which may be considered a direct natural antecedent of the parachute, and the maple seed, a natural prototype of the autogiro. Of considerable historical interest, because it demonstrated to aviation pioneers the feasibility of constructing a true self- stable tailless airplane, is the gliding seed of the Java palm tree, zanonia macrocarpa. These will be discussed later in this report.

Although winged insects were the first creatures to fly, our subsequent discussions will primarily focus on the developments of the flying capabilities of birds.

Flight capability opened up new sources of food, made escape from earthbound predators easier and increased the safety of living and breeding quarters. Impenetrable barriers such as mountains, oceans or rivers became easily navigable. Ultimately flight made it possible to follow favorable climates and changing food sources by means of seasonal migrations. Probable steps in the evolution of flight in birds are discussed below.

The initial steps in the evolution of flight were fundamentally driven by the needs of survival. These needs included safety from predators for both the individual and their offspring and more effective means of foraging. The early flight capabilities included parachuting and rudimentary gliding abilities. The enabling anatomical changes included developing the fundamental structure of the wing including the incredible concept of the feather.

The next series of steps in the march of evolution provided more efficient gliding flight with some maneuverability and the initiation of slight flapping flight. These provided the ability to determine the direction of the glide and stabilizing movements for turning and landing. The anatomical changes included development of neuromuscular control for coordination wing of wing movements and more effective wing geometry shapes.

Subsequently evolutionary developments provided increased flight functionality and better flapping flight performance with some degree of maneuverability. The associated anatomical developments included better neuromuscular control and more sophisticated wing aerodynamic characteristics. Following evolutionary steps have provided the ability to fly "higher, faster and farther" by providing flapping flight with high maneuverability soaring and hovering capabilities.

The varied developments of the eyes of predator birds and the eyes of birds that are the targeted prey are an example of co-evolutionary developments. Most birds cannot move their eyes, Birds of prey have eyes on the sides of their heads and have a wide visual field, useful for detecting predators, while those with eyes on the front of their heads, such as owls, have binocular vision and can accurately estimate distances when hunting.

Many avian species focus on distant objects preferentially with their lateral and monocular field of vision. Consequently, birds will position themselves sideways to maximize visual resolution. For a pigeon, resolution is twice as good with sideways monocular vision then with forward binocular vision, whereas for humans the converse is true. When a prey type bird turns their head away from an object they are doing so to obtain a more accurate view. 
Nature's flyers as well as man's air vehicles can be described fundamentally as systems of systems. Major subsystems such as aerodynamic, structures, flight controls, "propulsion", "mechanical", "navigational", "fuel" systems, "air conditioning", and "safety / security" systems inherent in man's flight vehicles have parallels within Nature's flyers. There exists strong synergism between all of the functionally interdependent component subsystems. Prior developments in one subsystem are often both enabling and necessary for subsequent advancements in other subsystems. Consequently "technology" advancements in Natures flyers and in aircraft include by necessity include multiple sequenced and serendipitous developments. The "survival of the fittest" selection process for nature implies that each subsystem is in itself an optimum solution within the confines of the overall optimized system.

The unending process of evolution driven by the "survival of the fittest" is molded by local environmental effects and the demands of co-evolution including both responsive developments and those that provide competitive advantages. Consequently nature has produced many unique acceptable flying designs as evident in the approximately 8000 bird species, 1000 species of bats and 350,000 species of flying insects.

Birds are dramatically different from all other living creatures. Feathers, toothless beaks, hollow bones, perching feet, wishbones, deep breast bones and stump like tailbones are only part of the combination of skeletal features that no other living animal has in common with them. Some of the most dramatic evolutionary developments included the highly sophisticated structural and neuromuscular control adaptations necessary to provide pitch, roll and yaw stability with a high degree of maneuverability. If one has the opportunity to observe kestrel statically hovering on up flow air currents on the windward side of a steep hill. Even though the air currents are moderately gusty, the kestrel is able to keep its eyes and head position remarkably fixed in space allowing continual and total focus on its potential prey. This is an excellent example of the impact of a bird's evolutionary structural and neuromuscular control adaptations and the resulting wing and tail movements. This is also an important goal for life "Keep your eye upon your goal"

\section{EVOLUTION OF TECHNICAL FLIGHT}

It is well documented that the more successful of the earlier pioneers of manned flight were inspired by natures flying creatures and objects and were well versed in the then current understanding of flight mechanics. The concept that the inspiration of natures flyers lead to experimentation, then the realization of manned flight and ultimately leading to the proliferation of flight capabilities through many airplane concepts is often the traditional view of the history of flight. However a more expanded view of the history of flight should extend from the origin of flight in nature to the present day. Nature's evolutionary processes and man's technology development are all bound together by the underlying requirements that each must obey the same fundamental laws of physics, chemistry - and economics.

Man's desires, thoughts, and efforts to fly have occurred not just over the past "Century of Flight", but over a period of hundreds of years. As it will be shown, this evolutionary period was highlighted by the enhancement our Knowledge of Flight Dynamics (KFD), our Understanding of Flight Dynamics, (UFD) plus the sequential developments of critical and necessary supporting technologies.

The initial flight dynamic "tools" that were available to the early pioneers of flight include the information, ideas and interpretations that they gleaned from their observations of Biological Flight Dynamics (BFD), that is the flight of birds. Otto Lilienthal (circa 1890) who is considered by many to be the pioneering father of flight stated "In order to discover the principles which facilitate flight, and to eventually enable man to fly, we must take the bird for our model" -. This visual information formed the basis of the Knowledge of Flight Dynamics (KFD) from which the early flight pioneers formalized their Understanding of Flight Dynamics, (UFD). It should be noted that knowledge and understanding are not the same, nor is all knowledge absolute, accurate or factual.

\section{EARLY UNDERSTANDINGS OF AVIAN FLIGHT}

It is interesting to examine the details of the state of knowledge of the physics of bird flight as recorded in books that were published in the time period of the Wright Brothers initial flights. Man's concepts of the nature and the physics of avian flight gradually developed from endless hours of marveling at the flight of birds over centuries of time. We have identified this source of information as BFD (biological flight dynamics). Early observations formed the basis of the evolving knowledge, KFD and understanding, UFD (not necessarily correct) that ultimately lead to man's initial attempts to fly. 
One of the earliest recorded pictures of the observed nature of flight is a cave painting from about 11,000 years ago, of what appears to be a bird landing. The picture suggests that the artist had a rather accurate understanding of the use of wings during landing, including what appears to be the extended alula.

DaVinci's well known sketches of bird flight from about 1500 show his interpretation of the characteristics of the flow around the bird. DaVinci pictures also shows the tail being deflected as a stabilizing mechanism. It is generally believed that these sketches were based more on his understanding of the physics of flight that on any particular flight observation.

Borelli described his concept of the manner by which birds fly in his masterpiece "De Motu Animalium" that appeared after his death in about 1680. "Birds fly by beating the air with their wings. They jump as it were through the air just as a person can jump on the ground ----- Wing beats compress the air and the air bounces back."

Borelli's understanding that the tail moved up and down to provide pitch control differed from the previously accepted belief advocated by Aristotle, that the tail acted as a rudder. Borelli also stated that birds change their horizontal direction by beating the left and right wings at different speeds similar the way that a "rower alters course by pulling harder on one oar than the other".

A very significant supporting technology development that provided valuable insight into the nature of flight was the chronophotographic gun that Etienne-Jules Marey perfected in 1882. With this instrument Marey was capable of taking 12 consecutive frames a second, and the most interesting fact is that all the frames were recorded on the same picture. With this instrument, it was then possible to observe the intricate motions of a bird or insect in flight. Marley's photographs were an early form of Visual Flight Dynamics, VFD.

Marley also made movies at high speed (60 frames per second). He is widely considered to be a pioneer of photography and an influential pioneer of the history of cinema. During the 1860s Marey threw himself into the study of flight, first of insects and then birds. His aim was to understand how a wing interacted with the air to cause the animal to move. He also devised some ingenious apparatuses based on his graphical method, such as a corset which allowed a bird to fly around a circular track while recording the movements of its thorax and wings.

Otto Lilienthal published the results obtained by him, working in conjunction with his brother, after long years of quiet scientific study and experiment, in 1889. This book contained the "discovery" of the driving forward of arched surfaces against the wind. Lilienthal said "The problems why a flying bird does not drop to the ground, how it is sustained in the air by an invisible force, may be considered fully solved so far as the nature of this supporting force is concerned." Lilienthal's sketches of the shapes of various bird wing geometries indicate that he had a obtained a rather thorough understanding of the flight features of a bird. The Lilienthal brothers spent a period of approximately 5 years over which they conducted approximately 2000 glider flight although their total flight time was less that 5 hours.

Five methods of bird flight were distinguished in the period in which the Wright Brothers entered the scene. The first method was called "rowing flight" (corresponding to the modern day vernacular of flapping flight), "was formulated by a combination of chronograph measurements together with a series of photographs. The photographs were obtained simultaneously from three directions showing the showing the movements of the wings at various sequential moments." (The early concept of early flight related the mechanics of flapping flight to the motion of rowing a boat. This is substantially different that the actual mechanics of flight.)

The second method called Gliding flight was defined as "rowing flight interrupted by the passive flights - the gliding. During gliding the flapping of the wings is halted, and the flight is sustained by the kinetic energy generated during the rowing flight". (This definition corresponds to our present day concept of bounding or intermittent flight).

The third method was called soaring. "During soaring, the bird remains over a point on the ground without flapping its wings; soaring is rendered possible by upward currents of air, forming over wooded land and on rugged rocks. The activity of the muscles is confined, in this case, to feeble balancing turns of the stretched wings about the body longitudinal axis."

The fourth method was called sailing. "Sailing is seen frequently with sea gulls following ships or progressive waves This movement is caused by the wind, reflected upwards after striking the sails or crests of the waves, holding the bird at a constant height and at a constant distance away from the sail or the wave crest, as the case may be. The difference between sailing and soaring is, that the animal not only remains at a constant height, but in the former case also is driven forwards."

xxiv 
The fifth method was called circling. The "explanation of the circling of birds is attended with especially great difficulties". Apparently the physics of thermals caused by local uneven heating of landmasses was unknown at that time. These thermals result from a central ring of revolving air with a core of rising colder air. The birds circle to remain in the core of rising air and then glide between other thermals.

It is interesting that there was no specific mention of hovering, either as a form of active flight in the case of humming birds rapidly beating their wings, or as a form of passive flight as in the case of the Kestrel riding rising upward currents over a steep hill.

\section{MAN'S EARLY FLIGHT CONCEPTS}

The earliest concepts and attempts at flying were all based on trying to directly emulate the flight of birds. Leonardo said that "a bird is an instrument working according to a mathematical law. It lies within the power of man to make this instrument with all its motions." Leonardo like many of the early pioneers of flight that followed, based on their observations of birds, believed that in order to fly, man would need a pair of flapping wings. These devices became known as ornithopters. DaVinci's concept of an ornithopter was developed in the 1486 to 1490 time period, However there is no evidence that he actually built or tested such a concept.

Karl Meerwein was the first to estimate the size of a wing surface necessary to support the weight of a man using as a basis the weight and corresponding wing area of birds. Taking the wild duck as his model, he found that a man, weighing $200 \mathrm{lbs}$. with the machine, would require a surface of $126 \mathrm{sq}$. ft. His apparatus consisted of two light wooden frames covered with calico. The pilot was fastened in a horizontal position in the middle, with a balancing rod in front of him, which worked the strokes of the wings when pressed by the body. Meerwein apparently made one unsuccessful experiment in 1789.

Friedrich von Drieberg was the first to acknowledge that man has the greatest power in the muscles of the leg, and must use these for the movements of flight. Up until this time it was commonly assumed that the wings must necessarily be moved with the arms. Drieberg's concept consisted of a bat-like flying apparatus in which flight was to be obtained by flapping the wing by treading with the feet, while lying horizontally.

Edward Frost constructed an ornithopter made of willow, silk and feathers supported on a wooden frame. When his ornithcopter was suspended from a tree it was said that it would rise slightly with every beat of the wings. The entire contraption was much too heavy to ever fly. He built his last ornithcopter in 1904, a year after the Wright brothers first flew. Frost later became the president of the Royal Aeronautical Society.

The earliest known idea for flight with fixed wing geometry as in today's airplanes is the 1799 aircraft design by George Cayley which was sketched on a small coin. Cayley's design had fixed wings for lift, a movable tail for control, and rows of "flappers" beneath the wings for thrust.

Alphonse Penaud in 1871 built a planophore, a 20-inch long monoplane with a pusher propeller powered by a rubber band. It flew 131 feet in 11 seconds becoming the first flight of an inherently stable aircraft. In 1874 Bishop Milton Wright bought one of Pénaud's toy helicopters. He took it home to his boys, Orville and Wilbur. And, right there, Pénaud ultimately changed the course of history. While many of the early glider concepts were dangerous exercises of futility, others begin to add to the accumulation of knowledge of the critical elements for successful flight.

Pilcher built and tested a number of glider designs between 1895 and 1899 when after a structural failure; he was killed in the collapse of his last glider. His experiments provided a series of important results:

- Too much wing dihedral reduced stability in side winds.

- Too low center of gravity makes the apparatus very difficult to control.

- A flying machine can safely be raised by towing it against the wind like a kite.

- Light wheels at the front are convenient to move the machine about and to absorb shocks in landing.

Le Bris built a glider which was inspired by the shape of the Albatross. The glider consisted of a wood frame and was covered in cloth. The pilot (Le Bris) sat inside, almost like in a canoe, and used levers to operate the movements of the wings and tail. This invention which he patented in 1857, was the first flight control concept. In 1856 he briefly "flew" the glider was put on top of a cart which was attached to a horse that ran against the wind. At this point, the Artificial Albatross was released from the cart and began to rise into the air. The Albatross glider became the first ever to be photographed, albeit on the ground, by Nadar in 1868 . 
Chanute after experimenting with various mono-wing gliders, started to experiment with various multi wing concepts. The concepts were initially based on kite designs that exhibited stable flight characteristics. He ultimately ended up with his biplane box-wing concept. Chanute in time became a mentor to the Wright brothers. The wing planform geometry which the Wright brothers choose for their gliders and also for the Wright flyer, was very similar to Chanute's double decker box wing.

The imaginations of the early aircraft designers were almost unlimited in scope. These early aviation pioneers studied the flight characteristics of every conceivable type of flying animal-birds, insects, bats, flying fish, even flying foxes. The Avion III was designed in 1897 and modeled after the geometry of a bat. The Avion III (Éole III) was a primitive steam-powered aircraft built by Clément Ader between 1892 and 1897, financed by the French War Office. This aircraft retained the same basic bat-like configuration of an earlier aircraft, the Éole. The Avion III was equipped with two engines driving two propellers. The propellers actually had a feather like structure. The Avion was equipped with a small rudder as means of directional control. Trials of the aircraft began at the Satory army base near Versailles on October 12, 1897, with the aircraft taxiing along a circular track. The first actual flight was attempted on October 14, 1897. The flight ended almost immediately in a crash without ever leaving the ground.

\section{FLYING SEEDS}

Dr. McMasters stated "Plants mastered the art and science of aviation long before Orville and Wilbur Wright propelled their frail craft into the air". This is evident in the concepts that nature has developed to enable seeds to navigate to suitable soil. If a tree dropped its seeds straight down, the seedlings would have to try to grow in the shade of the parent tree and would soon choke each other out. Seeds need to be carried away from its parent tree or plant and this now is accomplished in a variety of ways.

The most interesting aerodynamic example is probably the winged Zanonia macrocarpa seed. This kidney-shaped seed comes from a large vine of the cucumber family. It grows in the dense, moist jungles of Indonesia and has adapted its reproductive processes to a region in which there is no wind to distribute the seeds. The vine climbs 150 -foot trees, and near the top, the Zanonia seed develops with two curved wings, transparent, gleaming, and very elastic. The seed-a kidney-shaped platform when released, begins its glide, rising on thermals from the jungle heat, and finally landing at a considerable distance from its point of departure. One professor described the Zanonia glider in this way: "Circling widely, and gracefully rocking to and fro, the seed sinks slowly, almost unwillingly, to the earth. It needs only a breath of wind to make it rival the butterflies in flight." The Zanonia seed can perform amazingly long glides, during which it demonstrates basic inherent stability. Flights of up to $6 \mathrm{~km}$ from the vine have been recorded.

The aerodynamic features of the Zanonia macrocarpa seed include:

- Swept wing and forward CG for longitudinal stability (reduce pitch-up tendency)

- Swept wing and reflexed trailing edge to avoid pitch-up

- Reflexed trailing edge to provide quicker stall recovery

- Drooped leading edge for higher CLmax

- Dihedral for roll and yaw stability

- Large aspect ratio $=3 \sim 4$ with a lift/drag ratio of 3 to 4

- Optimum center of gravity location for lowest rate of descent or highest duration of flight

It is interesting to know that the center of gravity of the winged seeds is located at an optimal position at which the respective seed can fly at the lowest rate of descent or the highest duration of flight

A number of the early experimenters with tailless aircraft were inspired by the Zanonia's flying qualities. Igo Etrich adapted the principles he gleaned from his observation of the Zanonia seed to the design of his Leaf design in 1906.

DiVinci utilized the concept of the spinning seed to formulate his idea of the "air screw" which is considered to be the forefather of the autogiro, the helicopter as well as the propeller. Naturalist Christian de Launoy and his mechanic Bienvenu, about whom very little is known, developed a coaxial model of a simple helicopter powered by the tension in a bow. This concept was also the first counter-rotating propeller design.

A Large number of plants such as the dandelion use Nature's version of the parachute to disperse their seeds. The very light seeds of the plant are attached to relatively large fluffy plumes that are released from the plant with a slight breeze. The high drag of the fluffy plumes results in very low sinking rates allowing the seeds to be blown and dispersed far from the plant. The first known written account of a parachute concept is contained in da Vinci's notebooks (cl495). The 
parachute concept that he conceived consisted of a cloth material pulled tightly over a rigid pyramidal structure. DaVinci never made nor tested his device. The first recorded successful test of such a parachute was made in 1617 in Venice by the inventor Fausto Veranzio who had examined Da Vinci's rough sketches of a parachute, and Fausto set out to implement a parachute of his own. Twenty years later, he implemented his design and tested the parachute by jumping from a tower in Venice in 1617. In World War I and World War II the classic parachute was widely used. During the early space projects, Rogallo developed a single membrane flexible wing, known as the parawing. Large parawings were designed for recovery of reentry vehicles. The parawing parachute was designed for maximum lift as opposed to the maximum drag of conventional parachutes. The parafoil was invented in the middle 1960's by Domina Jalbert, a kite maker. The parafoil or ram-air parachute is a deformable airfoil that maintains its profile by trapping air between two rectangular shaped membranes, sewn together at the trailing edge and sides, but open at the leading edge. Several ribs are sewn to the inside of the upper and lower surfaces, maintaining an airfoil cross section in the spanwise direction.

\section{KNOWLEDGE, TECHNOLOGY AND TOOLS FOR THE WRIGHT FLYER}

Let us now examine the relationship between the previously discussed aerodynamic tools and the development strategy used by the Wright Brothers in developing the Wright Flyer. When the Wright Brothers set as a goal, the development of the first powered aircraft they initiated their process by a search for all available knowledge of prior attempts to fly. Wilbur wrote a letter to the Smithsonian Institution requesting information and publications about aeronautics. Drawing on the work of Sir George Cayley, Chanute, Lilienthal, Leonardo da Vinci, and Langley, they began their flight experiments that year. They also built a strong networking relationship with Chanute who "believing that the surest method is first to study past failures ---- made an investigation of the records of all the experiments,, which had been tried during the last two or three hundred years, in the endeavor to imitate the birds. This resulted in a number of technical articles which swelled into a book, in which the attempt was made to eliminate the causes of each failure; for up to that time there had been nothing but failures". Mr. Chanute in 1897 had published what may be considered to have been the state of the art understanding of ten critical elements that he considered to be critical to achieve successful powered flight.

1. THE SUPPORTING POWER AND RESISTANCE OF AIR (Ability to Predict Lift and Drag)

- We are now enabled to calculate with some confidence the support (lift) which may be obtained by gliding at any given speed upon the air, and the power required to overcome the resistance (ie drag). (Based on empirical formulae of Duchemin and Langley's experiments)

- More encouraging (lift) coefficients for concave surfaces have been obtained by Lilienthal in his experiments.

2. THE MOTOR, ITS CHARACTER AND ITS ENERGY.

- For the first time the realization of a sufficiently light motor for a dynamic flying machine seems to be within sight.

- It now seems probable that this will be accomplished with a petroleum engine.

3. THE INSTRUMENT FOR OBTAINING PROPULSION.

- All sorts of contrivances have been proposed; reaction jets of steam or of compressed air, the explosion of gunpowder or even nitro-glycerine, feathering paddle wheels of varied design, oscillating fins acting like the tails of fishes, flapping elastic wings like the pinions of birds, and the rotating screw.

- Mr. Maxim and Professor Langley have made many experiments to determine the best form, speed and pitch of the screw (propeller)to obtain thrust from the air, and have materially improved that instrument,

- $\quad$ The Screw (propeller) seems likely to be the best device.

4. THE FORM AND KIND OF THE APPARATUS.

- Almost numberless projects have been advanced, but they can all be classified under three heads.

- Wings to sustain and propel. (Ornithopters)

- Rotating screws to lift and propel, (Helicopters)

- aeroplanes, to consist of fixed surfaces driven by some kind of propelling instrument.

- $\quad$ The first two have been the first to be proposed and experimented with. They have many warm advocates at the present time, 
- Practical experiments made within the last five years seem to indicate that success will first be achieved with aeroplanes,

5. THE EXTENT OF THE SUSTAINING SURFACES. (ie. what is the required wing area?)

- The problem, relating to the extent of surface required to support the weight of a man, has caused in the past active controversy and gathering of data.

- It was perceived that in consequence of the law inherent to solids, the surfaces will increase as the squares, and the weights as the cubes of the homologous dimensions; it might well be that the additional relative weight due to the greater leverage should make it impossible to compass any larger flying machine than existing birds.

- A distinguished scientist published an article in which he flatly took the ground that an artificial flying machine was impossible for three reasons:

1. Nature, with her utmost effort, had failed to produce a flying animal of more than fifty pounds in weight.

2. That the animal machine was far more effective than any that man may hope to make.

3. That the weight of any artificial flying machine could not be less, including fuel and engineer, than 300 or 400 pounds.

- The experiments of Lilienthal, demonstrated that a man's weight can be well sustained, at 22 to 25 miles an hour, by an apparatus with an area /weight ratio $\simeq 0.75$

- This apparatus need not weigh more than from 23 to 36 pounds, without motor or propeller, so that if the latter weigh some 60 pounds more, --- carrying a man of about 150 pounds, upon sustaining surfaces of approximately 200 square feet in area. ( W/S 1.25)

6. THE MATERIAL AND TEXTURE OF THE APPARATUS.

- The sixth question relates to the material to be selected for the framing of the machine, for the motor, and to the texture of the sustaining surfaces. Nature accomplishes her purposes with bone, flesh and feathers, but man has at his command metals, fuel and textile fabrics

- For a beginning wooden frames covered with textile fabrics will answer for a beginning.

7. THE MAINTENANCE OF THE EQUILIBRIUM.

- $\quad$ The seventh problem relates to the stability of the apparatus in the air, and especially in a wind.

- This equilibrium must be maintained at all angles of incidence and under all conditions of flight.

- Until automatic equilibrium is secured, and safety is ensured thereby, under all circumstances, it will be exceedingly dangerous to proceed to apply a motor and a propeller.

- Man will have to work out this problem thoroughly, if he is ever to make his way safely upon the air.

8. THE GUIDANCE IN ANY DESIRED DIRECTION. (Control Capability)

- $\quad$ The eighth problem relates to the steering. It has been generally supposed that this would be best effected by horizontal and vertical rudders,

- The experiments of Lilienthal, have shown that slight changes in the position of the center of gravity are immediate and effective.

- It might be preferable to provide moving mechanism within the apparatus itself, to shift the surfaces so as to bring back the varying center of pressure over a fixed center of gravity, and that in such care the operator need not move at all, except for the purpose of steering.

- Two forms of apparatus have been evolved, each equipped with a different device, which are now believed to be materially safer than any heretofore produced.

- This problem cannot be said to be fully worked out, but it is not that a good deal of experimenting will be required, and that such experiments will be fraught with danger.

9. THE STARTING UP UNDER ALL CONDITIONS. (Takeoff capability)

- A really adequate practical flying machine will have to possess the power of starting into the air under all conditions

- Three principal methods have been experimented with:

xxviii 
1. By acquiring speed and momentum using such appliances as railway tracks

2. Utilizing the force of the wing.

3. By the reaction of rotating screws --- this will eventually supersede the two others.

- $\quad$ This problem is as yet unsolved.

10. THE ALIGHTING SAFELY ANYWHERE. (Landing Capability)

- Alighting safely anywhere is of vital consequence and is also an unsolved problem.

- The best method proposed involves the selection of a smooth soft piece of ground and the alighting thereon at an acute angle. (Smooth runway)

- It would be preferable ---- to imitate the maneuver of the bird who stops his headway by opening his wings wide, tilting back his body back and obtaining the utmost --- retardation from the air before alighting upon the ground.

- It would be preferable to utilize the reaction of a rotating screw to diminish the forward motion.

- [It is interesting to note that the recommendations proposed by Chanute are quite similar to present day landing configurations and procedures including high lift systems with extended leading and trailing edge flaps, spoilers and reverse thrust]

Chanute went on to say "These last two problems - the rising and alighting safely, without special preparation of the ground - seem very difficult and are probably the last of which will be worked out."

The general common "Expert" belief at the time when the Wright brothers started the pursuit of their dream was that powered manned flight was not possible. In spite of this prevailing negative mental environment, the Wright brothers believed in their dream and in a short period of three years succeeded. Their accomplishment provides a vivid example of two powerful messages:

1. "Believe you can, or believe you can't, either way you will be right"

2. "If the dream is big enough the facts don't count"

This was the "current" technical knowledge base and expert advice that formed the understanding of flight dynamics upon which the Wright Brothers launched their systematic technology and experimental developments that in a relatively short period of time achieved a first time accomplishment, that many had thought to be impossible - manned powered flight. The configuration features and development process followed the ten critical issues and development guidelines defined by Chanute. In 1900, 1901, and 1902, Wilbur and Orville Wright, achieved a considerable advance over all previous flying results. They were bold enough to be the first to place a man prone upon a gliding machine, instead of upright (for safety in alighting), and they used wing surfaces twice the area which previous experimenters had found it practicable to handle in the wind. Following their first glider in 1900, they discarded the tail, and substituted for it a hinged horizontal rudder at the front, which could easily be operated by the pilot while under way. Their theory was that the pilot should constantly balance and guide the machine by the action of the rudder, steering to the right or left by warping one wing or the other using light control strings leading to his hands. The control of the machine by the rudder in front was found to be even better than had been hoped, and the landings were safely made at speeds of $10 . \mathrm{m}$. per second. The experiments of 1902 marked another great advance and mark a decided advance in the techniques of flight. The apparatus could now be controlled so well that Wright brothers deemed it safe to pass on to the construction of a full flying machine equipped with a motor and propeller. They faced another seemingly daunting obstacle, the necessary lightweight engine did not exist. Consequently they designed and built the first lightweight aluminum engine. They also designed and built their own propeller. This was done in 1903, and on the 17th of December of that year, after many trials and modifications, they had the satisfaction of making four dynamic flights from level ground against a wind of 10 $\mathrm{m}$. per second-the first flight being of about 12 seconds, and the last of 59 seconds, when $260 \mathrm{~m}$. were covered at a height of about $2 \mathrm{~m}$. from the ground.

\section{MORE EXPANDED VIEW OF THE EVOLUTION OF FLIGHT}

The development of our flying vehicles dreams, visions, attempts and ultimate achievement were enabled by the progressive synergistic developments in aerodynamic concepts and tools and other critical technologies developments. 
The evolutionary events leading to manned flight occurred over thousands of years. For as long as man has harbored the desire to fly, many attempts were made to emulate the flight of birds initially by strapping on some apparatus that had some resemblance to a bird and then leaping off a tower or other high prominent location. This type of event was repeated over and over, but seldom by the same person. These Real Fluid Dynamics, RFD, experiments, which we will define as manned flight experiments, have occurred over thousands of years. Most of these early experiments failed, many of which suffered serious consequences. Lilienthal's and Chanute's numerous glider experiments represent the first extensive exploratory studies of manned flight.

The Fundamentals of Fluid/Flight Dynamics, FFD, equations were developed over a period of approximately a thousand years before the Wright Brothers. These include all the contributions by daVinci, Euler, Bernoulli, Navier-Stokes as well as boundary layer theory, the concept of circulation and linear theory formulations. However these developments awaited the development of the digital computer and consequently, had rather little significance in enabling early powered flight. Computational Fluid Dynamics, CFD, did not come into existence until about 1960. The impact of CFD, since that time, has become incredibly significant.

The earliest form of Experimental Fluid Dynamics, EFD, activities utilized whirling arm mechanisms. These did provide some basic understanding of lift and drag forces. The Wright Brothers built one of the first wind tunnels. Their experiments provided valuable information and data that were used to support their flight experiments. Two of the other critical enabling technologies in addition to the wind tunnel, included a fundamental understanding of Stability \& control Flight Dynamics, SFD, and the development and flight validation of simple but effective control mechanisms. In addition, the Wright brothers built the first light weight aluminum engine which they used for the Wright Flyer of 1903. This development process leading to the first manned flight clearly illustrates a typical feature of the development of new technologies and concepts. This is the requirement to advance on many disciplinary or technical fronts.

Following the pioneering developments of the Wright Brothers, the demand soon arose for greater flight capabilities. The further development of the aerodynamic tools, together with the developments in other technologies, resulted in dramatic increases in the performance and operational characteristics of aircraft.

The two most critical tools of the aerodynamicist, (KFD and UFD), are intimately related but fundamentally different. Knowledge of Fluid/Flight Dynamics is similar to a collection of pieces and perhaps partly assembled pieces of a great puzzle. The collection generally may be lacking some of the key pieces. In addition some of the pieces may be invalid or from a different puzzle. Our understanding, UFD, is the image that we create by assembling the pieces we have accumulated as well as inferring the nature of the missing pieces. Man's knowledge and understanding of the nature, of biomechanics of flight has evolved through the systematic development and utilization of the engineering tools and processes,, as well as critical synergistic and enabling developments in many other technical disciplines. The expanded use of our tools have provided many additional pieces to out knowledge and understanding puzzle that are reflected in the increased capabilities and sophistication of our modern flight vehicles.

The designs of early propeller commercial aircraft were innovation driven with the primary goal of increasing aircraft performance. That is to fly higher, faster and farther as well as to become bigger.

The introduction of jet powered swept wing aircraft provided revolutionary increases in aircraft size, cruise speed, cruise altitude and range. The cruise speeds and altitudes have remained essentially constant for subsonic aircraft jet aircraft. The early jet aircraft designs were determined by the aircraft manufacturer with inputs from the airline customers. Technology advancements were focused on increased functionalities including aircraft growth capabilities, operating economics and range.

The designs of the third generation of commercial aircraft were increasingly driven by customer inputs with supplier options and the areas of technology development were focused on various efficiencies including family growth concepts, improved economics, increased range and aircraft noise reduction.

The new generations of commercial aircraft designs will be both customer and society driven. The manufacturer will provide design options determined by strategic assessments of economic risks and opportunities. The technology focus areas will include in addition to those of previous aircraft, more efficient manufacturing processes, fuel efficiency and reduced emissions, travel time and affordability, safety and security, and improvements in the ATM system. Because of the highly competitive nature of today's market place, one of the primary goals of new aircraft is that of basic company survival. Unless a new airplane is the best offering to the airlines, lack of sales could force a company out of business. 
If we compare the technology drivers of nature with the technology drivers for commercial aircraft we arrive at the observation. The evolutionary driver for nature's flyers was initially survival, and then gradually progressed through stages of efficiency, functionally and ultimately higher, faster and farther. The technical driver for manned commercial flight, however, appears to have progressed in the opposite order. I am not sure if this is biologically accurate, but it is an interesting observation.

\section{OPPORTUNITIES AND NEEDS FOR INNOVATION}

Aerodynamics together with structural and manufacturing considerations largely define an airplanes exterior contours. The technological progress in aeronautics is often associated with size and shape of the aircraft. It can be argued with some degree of validity, that the vast majority of existing aircraft were established approximately 65 to 70 years ago. Ingo Rechenberg said that he finds it "very remarkable that after 100 years development a modern aircraft still looks like a bird: a spindle body, the wing in front and the elevator behind. That's the solution of biological evolution and that's still the basic concept of a modern aircraft." However this certainly does not mean that man has exhausted all possible aircraft related innovative or creative technology developments.

The needs for continued technical innovation and development for aircraft far exceeds just the external shape or operating procedures. The needs for technical innovation permeate every element of the systems of system. Some of the general critical areas for which technology developments are in need commercial air transportation include:

- Factors that affect the costs to build, own, operate and maintain a commercial aircraft

- Aircraft community noise reduction

- Design and Manufacturing Processes, (Cost to Build)

- Emissions / Fuel Efficiency

- Travel Affordability / Time / Comfort

- Safety / Security

- Air Traffic Management

Where do we go from here in the next 100 (or even 20) years? There are at least three possible answers all of which are likely one way or another:

- Keep running harder and harder (i.e. doing what we have been doing) to develop innovation solutions for today's classes of aircraft.

- Schedule a breakthrough (e.g. a possible Sonic Cruiser II via large reductions in sonic boom intensity and "aerospace plane" technology) or an invention (e.g. economically and logistically viable alternatives to fossil fuel propulsion schemes for transport aircraft).

- Start a whole new game - one in which the gap between the possible and the achieved is once again very large, e.g. the whole range of possibilities for uninhabited [combat] air vehicles (UAV/UCAV) type vehicles, which represent a complete fusion of traditional and emergent aerospace vehicle technology with "information and communications technology."

A general characteristic of technology development is the need to advance the technology on all fronts. Consequently each and every component technology or systems development becomes a critical element in the overall innovative development processes. With our view of an aircraft as an integrated system of systems, this implies that a technology development in one system no matter how seemingly small or unrelated, can become an important element in the overall system development. Consequently one should be open beyond their immediate technical discipline to any concept that offers potential improvements for the system as a whole

The complete report discusses various technology development strategies with recommendations for potentially more effective Industry, Government research facilities and Universities integrated activities.

\section{SIMILARITY ANALYSES AND ALLOMETRIC SCALING STUDIES OF NATURE}

Modern birds fully and elegantly embody a number of items that have been the subject of much research and development in aviation in recent decades. These items include mission adaptive wings of extreme sophistication, an advanced high-lift system, an active flight critical control system, a self-repairing/self reproducing composite structure, and fully integrated system architecture. There are many other technical areas of potential importance that are well demonstrated in natural flying devices such as the various uses of vortices for flow control, and the problems and benefits of controlled large-scale unsteady separated aerodynamic flows. We obviously have much to learn from nature's 
designs. Professor Robert J. Full, of the University of California, Department of Integrated Biology has suggested "Do NOT Mimic Nature - Be INSPIRED by BIOLOGY and use these novel principles with the best engineering solutions to make something better than nature." Following that wise advice, we will therefore explore a number of biologically related approaches for potential technical inspirations and design innovation.

To be inspired by nature it is important to understand how nature creations are affected by size, environmental and operational effects. A good place to gain such an understanding is through the application dimensional analyses and simple similarity principles.

The various physical quantities in the Mass-Length-Time system, MLT, can be expressed in a physiological system based on a characteristic length, L, for exploring the effects of size changes. The appropriate selection of a characteristic length can be rather ambiguous. Most often, therefore, the body mass of an organism is used as the reference index for the correlation of morphological and physiological characteristics, especially when attempting to compare similar but different creatures. By using the mass based physiological dimensions we can identify simple relations that can be used to gain some interesting insights into nature.

Birds are warm blooded animals and must maintain essentially a constant internal temperature. Heat loss for an animal is proportional to the surface area which is proportional to $\mathrm{M}^{2 / 3}$. The heat generating capability is proportional to the mass of the animal. The relative heat loss to heat generation ratio is therefore proportional to (Mass) ${ }^{-1 / 3}$. Smaller animals have an increasingly difficult task to maintain a constant temperature. This limits the smallest size for a bird as well as warm blooded animals. Because of their tremendous metabolic requirements the tiny hummingbirds, bats and mammals must eat a large amount of food. Hummingbirds eat roughly twice to thrice their own body weight in flower nectar and tiny insects each day. Consequently, if someone says "you eat like a bird", it should not be taken as a compliment. For the same temperature loss reasons there are no small mammals in the sea.

The square/cube law can also be used to explain the limit to the greatest height of a tree. The bending strength of a tree is proportional to its cross section area, The mass of the tree is proportional to the cube of its linear dimension. Consequently the taller the tree, the greater is the stress during a wind storm, thus limiting the height of a tree. Whales do not have to structurally support their own weight because of the buoyancy effect in the water. Therefore whales can be many times larger than even the largest land mammal.

The physiological mass based dimensions can be used to explore some size related effects on the performance of birds. Periodic events repeat themselves after a time T. For biological periodic motions the time scale is proportional to the $\mathrm{M}^{1 / 3}$. Wing beat frequency with units of $1 / \mathrm{sec}$ has physiological dimensions proportional to $\mathrm{M}^{-1 / 3}$. .

The length of the wing increases gradually with the mass ${ }^{1 / 3}$. The wing beat frequency increases greatly for small birds and insects. Therefore the wing tip speed which is equal to the product of wing semi-span times the rotation frequency is as shown by the physiological mass parameter is essentially constant of all of the birds and insects. Physiologically, the force that a bird might exert is proportional to its weight. The specific force which is the ratio of the force to weight, is independent of the size of birds. The same is true for insects. The thrust to weight ratio for birds is however less than one. This means that birds, with the exception of the hummingbird cannot just lift off from a surface. They must either jump to get airborne, propel themselves from some high object or run along the ground or water to gain enough speed to begin to fly. Insects, on the other hand, have thrust to weight ratios much larger than one and can therefore fly off a surface.

Let us now develop a relationship between cruising speed and weight of insects, birds and airplanes. Using the definition of lift coefficient as derived from dimensional analysis, wing loading (weight/wing area) is proportional to velocity squared: $\mathrm{W} / \mathrm{S} \sim \mathrm{V}^{2}$. From the previously discussed similarity relations, wing loading is proportional to weight ${ }^{1 / 3}$, so that: $\mathrm{W} / \mathrm{S} \sim \mathrm{W}^{1 / 3}$. Consequently, this implies that the cruising speed varies with weight to the $1 / 6$ power: $\mathrm{V} \sim \mathrm{W}^{1 / 6}$. The flight speeds of tiny insects through massive transport airplanes can be correlated with this simple velocity versus weight relation. There are twelve orders of magnitudes of weight variation (Newtons) from the tiny insects to the large transport aircraft and there is slightly more that two orders of cruise speed variation (meters/sec.).

The cruise speed of a bird or insect, must exceed the wind speed in order to make any progress. Mosquitoes and gnats will only fly in light breeze conditions. Since these light breeze conditions generally occur in the evening, "mosquitoes only come out at night".

We can use similarity relations to establish the approximate largest size for a flying bird. There is a strong correlation between flight muscle mass (and thus power available) and total mass of most birds. The mass bases physiological mass 
scaling parameters, the power required to fly increases approximately as the $\mathrm{M}^{7 / 6}$. If the available power is less than that required for flapping flight at a particular speed, then flight is simply not possible. If it exceeds the power required, then the excess power can be used for other demanding tasks such as maneuvering or climbing flight. Taking known data for a pigeon as an anchor, we can project the curve to the point where power available exactly equals the power required. The results indicate that the maximum mass of a flying bird is about $20 \mathrm{~kg}$ (44lbs). This is consistent with that of a barely able to fly South African turkey, the Kori bustard. Being able to develop a fundamental understanding of nature and also of physics is an essential element for identifying and / or conceiving innovative technology or design concepts.

\section{3. "BIONICS" AS A SOURCE FOR DESIGN INSPIRATION}

Bionics can be formally defined as the science of copying nature for a similar application or engineering solution for the benefit of mankind. This includes copying nature designs, operating procedures and flow control mechanisms.

The previously discussed Zanonia Macrocarpa flying seed is considered to be the biological inspiration for the flying wing. Dr. Lippisch wrote, "Nature had designed the flying wing thousands of years before man even thought of flight". Early aviation pioneers were impressed with the perfect flight of the Zanonia seed. In building craft light enough to soar in the wind, stability was the key. Lilienthal's glider of 1891 shows a distinct resemblance to the cucumber seed. The Horten Brothers and Northrop continued development of the flying wing in the 1940s. The early research together with numerous system technology developments ultimately led to the Northrop Grumman B-2 aircraft.

A recent bionic design example is the spiroid wing tip invented by Dr. Gratzer of Aviation Partners. This induced drag reducing innovative concept, was derived from the spread primary feathers of a large soaring type bird. Other bioinspired investigations have focused on efficient fuel saving flight techniques such as formation flying. For nature utilizing these energy saving flight techniques may mean the difference between achieving their destination or perishing along the way. There is some evidence that for large birds such as the Canadian goose the maximum sustained power (aerobic) is very close to the power required for flight. This implies that formation flight is not only a means to save energy and increase the flight range, but in some instances may be absolutely necessary even to fly at sustained power.

\section{4. "BIOMIMICRY” AS A SOURCE FOR DESIGN INSPIRATION}

Biomimicry can be defined as a science that studies nature's models and then imitates or takes inspirations from these designs and processes to solve human problems. The basic principle is to make nature's problem solutions usable for man. Nature, through billions of years of trial and error, has produced effective solutions to innumerable complex realworld problems and nature has done a very good job. "Any engineer must inevitably have respect for the excellence of the design that can be seen in biological system"s.

The creation of Velcro is a classic example of Biomimicry. As the story goes, after taking his dog for a walk, George de Mestral, a Swiss inventor, became curious about the seeds of the burdock plant that had attached themselves to his clothes. With a microscope, he looked closely at the hook system that the seeds use to the loops of his wool socks. He realized that the same approach could be used to join other things together. The result was Velcro. The Velcro type of fasteners have found rather wide spread usage even within the aircraft industry. Velcro is an example of an "irritation" being a source of invention. De Mestral asked the question "why" then proceeded to answer the question and then found a way to exploit the answer. This is a good model for anyone to follow as a source for innovation.

In 1982 botanist Wilhelm Barthlott noticed that water when landing on a lotus leaf formed spherical droplets that ran off the surface and in the process removed any dirt on the leaf. Upon further exploration he discovered in the lotus leaf a naturally self-cleaning, water-repellent surface. The secret lies in waxy microstructures and nanostructures that, by their contact angle with water, cause it to bead and roll away like mercury, gathering dirt as it goes. Barthlott patented his discovery, calling it the Lotus Effect. It has found commercial application in products like the biomimetic paint Lotusan. Infused with microbumps, the paint is reputed to repel water and resist stains for decades.

Curiosity concerning how a duck could stand or swim in very cold water without its legs freezing led to the discovery that nature has developed in the legs of a duck, a very efficient counterflow heat exchange system. Birds living in cold environments must conserve body heat in order to avoid hypothermia. However, blood flowing from the body core to the legs and feet carries heat that can be readily lost through the skin. To prevent such a loss, birds have evolved a counterflow heat exchanger system in their legs and feet. The blood vessels in the legs include arteries carrying warm blood down the legs to the feet, lie in close proximity to the veins carrying cold blood back from the feet. The cold blood 
in the veins gradually reduces the temperature of the blood in the arteries as it flows towards the feet such that the temperature is near ambient and results in very little external heat loss. In addition, the warm blood in the arteries heats up the returning blood from the feet in the veins so that the blood reentering the main body is at essentially body temperature. Therefore, even when a duck is standing in ice cold water, there is hardly any net heat loss to the body.

The principle of countercurrent heat exchange is so effective and ingenious that it has also been adapted in human engineering projects to avoid energy waste, e.g., by ensuring good ventilation of buildings while avoiding the loss of heat to the environment on a cold winter's day.

Another example of a nature inspired innovative design is the concept vehicle Mercedes-Benz bionic car developed by engineers, designers and biologists at Mercedes-Benz who worked hand in hand to develop a very design. The design was based on a sea dweller from tropical latitudes commonly known as the boxfish. The rectangular anatomy of the boxfish is practically identical to the cross-section of a car body. The fish is an excellent swimmer having extremely good aerodynamic characteristics and can move with a seemingly minimal amount of effort. Wind tunnel tests of a scale model of the Mercedes-Benz bionic car have yielded surprisingly very low drag. The boxfish is also a marvelous natural structural concept and is able to withstand high pressures as a result of its outer skin structural design consisting of tiny interlinked hexagonal bone plates which provide maximum strength with minimal weight and effectively protect the animal from injury. It can survive unscathed following collisions with corals or other sea dwellers. In consultation with bionics experts, the automotive researchers developed a computer-assisted process for transferring the growth principle used by nature to automobile engineering. It is based on the SKO method (Soft Kill Option). Computer simulations were used to configure body and suspension components in such a way that the material in areas subject to lower loads was reduced, and in certain instances, even eliminated ("killed") completely, while highly stressed areas were specifically reinforced. This bionic SKO process enabled an optimal component geometry to be identified which meets the balanced requirements of lightweight construction, safety and durability. The boxfish is a prime example of the ingenious inventions developed by nature over millions of years of evolution. The basic principle of the evolutionary developments is that nothing is superfluous and each part has a purpose and often several at once.

Large African termite mounds provide the incredible ability to maintain virtually constant temperature and humidity in their homes despite an outside temperature variation from $37^{\circ} \mathrm{F}$ at night to $108^{\circ} \mathrm{F}$ during the day. The column of hot air rising in the above ground mounds helps drives air circulation currents inside the subterranean network. The structure of these mounds can be quite complex. The temperature control is essential for maintaining the brood within a narrow temperature range, often only plus or minus one degree over a day.

Project TERMES (Termite Emulation of Regulatory Mound Environments by Simulation) scanned a termite mound, created 3-D images of the mound structure and provided the first ever glimpse of construction concepts that may likely change the way we build our own buildings. The Eastgate Centre is a mid-rise office complex in Harare, Zimbabwe, which was designed to emulate the temperature control concepts of the termite mounds. The East gate Center stays cool without air conditioning and uses only $10 \%$ of the energy of a conventional building of the same size.

\section{5. “NEO-BIONICS” AS A SOURCE FOR DESIGN INSPIRATION}

Neo-Bionics" is an innovation approach that utilizes biological evolutionary or optimization processes found in nature as the computational strategy for a computer aided design optimization with engineering constraints. Neo-bionics can be defined as"Computational Inspiration"

Some of the biologically inspired optimization techniques include

- Genetic Algorithms (GA)

- Particle swarm optimization (PSO)

- Evolutionary structural optimization (ESO)

- Bidirectional evolutionary structural optimization (BESO)

- $\quad$ Soft Kill Option, (SKO)

The following example illustrates how unexpected fundamental concepts can arise from robust configuration optimization using genetic algorithms, GA. In this example an evolutionary optimization algorithm was used to find the wing geometry for minimum total drag, and fit inside a geometric constraint box of fixed height and span.

The wing was described as a collection of variable length linearly tapered and twisted elements, whose aerodynamic characteristics were computed using a vortex lattice analysis. A random population of initially simple designs was 
initially developed. The optimizer quickly discovered that large span reduces drag, and after only 5-6 generations (with population size 500), and found the minimum induced drag for a roughly planar wing. As the span limiting constraint becomes active, the optimizer "discovers" winglets, adding vertical elements at the wing tips to further reduce vortex drag. Finally, after about 100 generations, the system finds an advantage to adding horizontal tip extensions to the winglets, forming a "C" shape at the tip that lies within the upper geometric box constraint.

This "C" wing design concept was investigated further and found to exhibit useful structural and control features in addition to the reduced vortex drag at fixed span. The concept was subsequently patented and is being studied for application to new aircraft concepts at Boeing, NASA and elsewhere.

The evolutionary structural optimization (ESO) method is based on the simple concept of gradually removing underutilized material from a structure so that the resulting shape evolves towards an optimum. The ESO method proves to be capable of solving size, shape and topology structural optimization for static, dynamic, stability and heat transfer problems or combinations of these. The traditional ESO method removes material from a structure based on von Mises stress or strain energy of each element. For certain construction materials, such as concrete and fabric, they are only suitable for sustaining compressive or tensile stress. The ESO method has been extended to the design of tension-only or compression-only structures. The validity of the ESO method depends, to a large extent, on the assumptions that the structural modification (evolution) at each step is small and the mesh for the finite element analysis is dense. If too much material is removed in one step, the ESO method is unable to restore the elements which might have been prematurely deleted at earlier iterations. Consequently, In order to make the ESO method more robust, a bi-directional ESO (BESO) method has been developed which includes both the adding and removing of material during the optimization process.

The BESO algorithm was applied to the design an optimized bench design. The top layer of the bench was defined as a non-design domain. The initial design had four support legs. By adding and removing material simultaneously, BESO quickly found an optimal solution.

The SKO, soft Kill Option is a relatively new method for structure optimization that was developed to transfer the growth principle used by nature to engineering structural design. In the book Design in Nature: Learning from trees, Prof. Mattheck introduced what he called the Principle of Constant Stresses derived from analogies observed in the growth of trees. He found that the trees adjust their growth in a fashion such that the stresses on the surface are equally distributed. Stress peaks that occur will be reduced by a stress proportional growth in that area. He also observed that in nature, all unnecessary material is avoided and that material decays where it is no longer needed.

Based on these bionic observations, he introduced what he called the Soft Kill Option (SKO). By varying the young's modulus in a structure, he rewards the elements that carry more of the load by increasing the young's modulus and simulating material growth in the area. He punishes the elements at lower stress states by decreasing their respective young's modulus. By this, the 'lazy' elements increasingly withdraw themselves from carrying the load and once they do not contribute significantly, he purges them from the set of elements. This process enables an optimal component geometry to be identified that meets the requirements of lightweight construction.

The SKO method has become an integral part of Daimler Chrysler's vehicle development engineering processes. In the case of a car door, for example, this honeycomb-design method increases stiffness by up to 40 percent, while the weight is reduced by around 30 percent, based on calculations using the SKO method. If the entire body shell structure is configured according to the SKO method, its weight is reduced by around 30 percent - while retaining its exemplary stability, crash safety and handling dynamics. The SKO method has since been used for producing components such as the engine support arms that are fitted on some rural-service buses.

It should be noted that the aforementioned structural optimization methods have no proof that they will achieve an optimal design but experience has shown that the application of these straightforward methods will result in lighter and durable structures. The weight saving efficient structural design concepts obtainable by these evolution based design methodologies clearly shows that bionics can make contributions to greater fuel economy and operational economics for both the automotive and aerospace industries through the development of lightweight efficient structural designs.

\section{6. "PSEUDO-MIMICRY” AS A SOURCE FOR DESIGN INSPIRATION}

Pseudo-Mimicry relates to technology developments or innovative concepts that are not directly inspired by nature, but have similar but unrelated functions. Sometimes we do not copy nature, but we re-discover our own inventions in a similar but unrelated concept of nature. We will extend this definition of pseudo-mimicry to include designs that may 
have similar functions but were not directly influenced by an awareness of nature's similar design. Since natures designs have been refined over periods of millions of years, finding a design or concept in nature that is similar to one of our creations tends to suggest that we are probably on the right track.

The Proteus is a twin turbofan high altitude multi mission aircraft powered by Williams International FJ44-2E engines. It is designed to carry payloads in the 2000-pound class to altitudes above 60,000 feet and remain on station up to 14 hours. Heavier payloads can be carried for shorter missions. It is intended for piloted as well as for UAV missions. Missions for Proteus include telecommunications, reconnaissance, atmospheric research, commercial imaging, and space launch. The Proteus is designed with long wings and a low wing loading needed for efficient high altitude loiter. It excels in stability and low noise. It is capable of dynamic maneuvers, needed to operate in adverse conditions. The crisp, short takeoff and landing uses the unique "three-mains" landing gear design intended to increase crosswind and wet runway capability without the use of spoilers. The shape of the Proteus is very similar but certainly unrelated to the Microraptor gui. The chicken-sized Microraptor, which lived in the early Cretaceous period 140 million years ago, had long flight feathers on its forelimbs and feet, and relied its a biplane-like wing configuration to swoop from tree to tree.

The cross section of a birds wing indicates a light weight structure sandwich design that nature developed using its' evolutionary version of Soft Kill Optimization. The design is very similar to that of a Warren truss as well as the structural concept used for the fuselage designs of the early aircraft. Construction of a Warren truss like structure features longerons, as well as diagonal and vertical web members. As technology progressed, aircraft designers began to enclose the truss members to streamline the airplane and improve performance. This was originally accomplished with cloth fabric, which eventually gave way to lightweight metals such as aluminum. In some cases, the outside skin can support all or a major portion of the flight loads. Most modern aircraft use a form of this stressed skin structure known as monocoque or semi-monocoque construction.

The aerodynamic concept of the leading edge slat on an airfoil or wing performs the same function as the alula that exists on the wings of some birds. Both concepts help to restore or retain attached flow around the leading edge and thereby increase the maximum achievable lift coefficients, CLmax. Birds as well such equipped aircraft use their respective leading edge devices to provide lower landing speeds

\section{7. “CYBERNETICS”AS A SOURCE FOR DESIGN INSPIRATION}

Cybernetics will be defined as the science of reverse engineering of nature using analytical tools and methodologies to examine nature in great detail to gain an understanding of natures designs, functions and operational procedures and thereby enable bionic or biomimicry innovations. John. McMasters stated that "Engineers, working closely with those from a range of scientific disciplines (e.g. zoology, botany, paleontology, neuro-physiology, geology, and particularly ecology), have much to contribute to increasing our understanding of flight in nature and engineering in general."

Cybernetics benefits from an integrated approach to assimilate results of independent and / or coordinated studies using the various tools of the aerodynamicist to develop the knowledge data base defining the mechanics of insect flight. The understanding formulated from the knowledge database can then be applied to the development of an artificial flying insect.

We have all probably observed at various times the magnificent aerobatic displays of large flocks of birds, which appear to be ordered patterns of chaotic undirected motion, often without an apparent purpose or global objectives. Similar types of swarming motion are displayed by insects as well as by schools of fish. A swarm of bees or a flock of birds can be assumed to consist of ' $\mathrm{N}$ ' number of agents. These autonomous agents are in some way co-operating to achieve a global objective. This global objective can include better foraging, constructing shelter, or serving as a defense mechanism. The apparent collective intelligence of a swarm emerges from actions of the individual agents. The actions of these agents are governed by local rules of interactions of the $\mathrm{N}$ agents. A kind of "self organization" emerges in these systems .

The individual (but autonomous) agent does not follow directives from a central authority or work according to some global plan. As a common example, a bird in a flock, only adjusts its movements to coordinate with the movements of its flock mates or more precisely the members that are its neighbors. It simply tries to stay close to its neighbors, but avoid collisions with them. Each bird does not take commands from any leader bird since there is no lead bird. Any bird can fly anywhere in the swarm, either in the middle or the front or the back of the swarm. Swarm behavior gives the birds some distinct advantages like protection from predators, and searching for food. 
Craig Reynolds, a computer graphics researcher, in 1986 created a deceptively simple steering program called boids. The boid model has in its implementation, simple rules to explain and predict the motion of a flock of birds. Each boid observes the following rules.

1. Boids try to fly towards the centre of mass of neighboring boids.

2. Boids try to keep a small distance away from other objects (including other boids).

3. Boids try to match velocity with near boids.

Flake later added a Fourth rule, a boid should move laterally away from any boid that blocks its view.

This simple model has been shown to accurately predict the motion of the flock and the agents within the flock. Swarm intelligence as predicted by the boid model provides a basis which makes it possible to explore collective (or distributed) problem solving without centralized control. A team of robots that could coordinate its actions like a flock of birds could offer significant advantages over a solitary robot. Spread out over a large area, a group could function as powerful mobile sensor net, gathering information about what's out there. If the group encountered something unexpected, it could adjust and respond quickly, even if the robots in the group weren't very sophisticated.

Jumping can be a very efficient mode of locomotion for small robots to overcome large obstacles and travel in natural, rough terrain. Professor Dario Floreano and his colleagues at the Laboratory of Intelligent Systems, Swiss Federal Institute of Technology have developed a novel $5 \mathrm{~cm}, 7 \mathrm{~g}$ jumping robot that can jump obstacles as high as more than 24 times its own height. It employs elastic elements in a four bar linkage leg system to allow for very powerful jumps and adjustment of jumping force, take off angle and force profile during the acceleration phase. This jumping mechanism is very similar to natures jumping mechanism of the grasshopper that was previously discussed.

\section{8. “NON-BIONIC" SOURCES FOR DESIGN INSPIRATION}

Although nature can provide numerous inspirations for innovative designs, that certainly is not the only source. We have the ability to innovate within ourselves by understand and applying fundamental knowledge related to the task at hand. We define non-bionic innovative technology developments or innovative involve concepts having no apparent similar parallel in nature. Familiar examples of non-bionic design innovations include laminar flow control, minimum drag due to lift elliptic load distribution, area ruled bodies, the variable sweep wing configuration, turbo jet and turbo fan engines.

\section{IDEAS ARE EVERY WHERE}

Ideas for innovation are everywhere as we have seen by the previously discussed biologically inspired innovations. Do you see a gecko' foot or do you see the potential for a super removable adhesive, a climbing robot, or a potential tall building fire rescue device? Do you see an abalone shell or a strong impact ceramic type material? Do you see a whale flipper or do you see an advanced wind turbine blade? Do you see a pine cones or smart clothing that adapts to changing temperatures? Do you see giant termite mounds or a passive cooling concept for large buildings such as the Eastgate Centre in Harare, Zimbabwe? Do you see a swamp or do you see the potential for a source for biofuel? Do you see a bat or do you see some of the many echolaction related technologies? Do you see a cat's shinning eyes that is due to tapetum lucidum that reflects visible light back through the retina? Or do you see such things as raised pavement marker and many other "retroflector" items.

Life is a journey full of many choices, obstacles and rewards. Our life and our career can each be filled with exciting discovers and blessed with wonderful achievements. It all depends upon the paths we take in our life journeys, on the choices we make, what we search for, what we observe, what we learn and the actions that we take.

- Learn to See and Not Just Look

- Learn to Hear and Not Just Listen

- Learn to Feel and Not Just Touch

- Learn to Understand and Not Just Know

- Learn to hunger for inspiration and Wisdom and to Never Get Full

- Learn to Wonder and Then Ask Why

- Learn to Succeed and Not Just Try

(by Brenda Kulfan 2008)

Most of all, be excited. There are many more problems to solve, concepts to create and flying vehicles to develop. 
Proc. of SPIE Vol. 7287 728701-38

Downloaded From: https://www.spiedigitallibrary.org/conference-proceedings-of-spie on 26 Apr 2023 Terms of Use: https://www.spiedigitallibrary.org/terms-of-use 